Research Article

\title{
Electrohydrodynamic Processing of p-Type Transparent Conducting Oxides
}

\author{
Yin Liu, Sureeporn Pollaor, and Yiquan Wu \\ New York State College of Ceramics at Alfred University, Alfred, NY 14802, USA \\ Correspondence should be addressed to Yiquan Wu; wuy@alfred.edu
}

Received 7 July 2015; Revised 7 November 2015; Accepted 15 November 2015

Academic Editor: Run-Wei Li

Copyright ( 2015 Yin Liu et al. This is an open access article distributed under the Creative Commons Attribution License, which permits unrestricted use, distribution, and reproduction in any medium, provided the original work is properly cited.

\begin{abstract}
Electrohydrodynamic processing is capable of synthesizing various materials in the form of porous/dense thin films, nanofibers, nanorods, nanobelts, and ribbons, which is highly favorable for functional oxides. The tailored microstructures and properties derived from electrohydrodynamic forming also give rise to new research interests on some classical oxides, such as transparent conducting oxides (TCOs). Here a case of feasible electrospray synthesis of classical $\mathrm{ZnO}$ is demonstrated with tailored p-type conductivity. Another p-type TCO, $\mathrm{CuAlO}_{2}$, was prepared by both electrospray and electrospinning methods and the processingderived electrical and optical properties are demonstrated. The last part of the paper discusses some emerging applications especially for $\mathrm{CuAlO}_{2}$ as potential nanobuilding blocks enabled by electrohydrodynamic processing.
\end{abstract}

\section{Introduction}

The electrohydrodynamic phenomenon, which describes the interaction between liquid and electrical field, has been discovered for over one hundred years. However, the incorporation of this phenomenon into practical material processing approaches has just become available in recent decades [1-4]. The basic concept lies in the fact that the liquid meniscus escaping the capillary tip under electrical field would deform into a conical shape (Taylor core), from where the submicrometric liquid jet is formed. The jet could either go through physical disruption after propulsion to form monocharged nanodroplets or maintain its single wire shape, mainly depending on the viscoelasticity and dielectric properties. The former is called electrospray, while the latter is electrospinning. These two techniques have been widely utilized in synthesizing a large variety of materials ranging from polymers, ceramics, and metals to composites [5-8], with the forms of thin films, nanofibers, and nanobelts. The electrohydrodynamic derived technique could also rival other nanoscale fabrication techniques due to its simple setup and versatile capabilities in tailoring the nanostructure and properties. On the other hand, since there has been growing research interest in nanobuilding blocks for some emerging technologies such as photocatalyst, thermoelectrics, batteries, and nanophosphors, this recalls the demand to employ electrohydrodynamic processing to fabricate classic and new materials in both low dimensions and various morphologies. Even though the electrohydrodynamic processing was originally designed for polymeric products, it is also capable of fabricating ceramics from either chemical solutions or suspensions. Table 1 lists some low dimensional oxide materials fabricated by electrohydrodynamic processing from previous reports. The main idea of fabricating the $\mathrm{n}$ - and $\mathrm{p}$-type oxides through electrohydrodynamic processing is to firstly prepare and deposit the precursor solutions containing the desired ion species on substrates and then calcine the precursors to initiate crystallization. Besides the merits of simple setup and cost-efficiency, the electrohydrodynamic processing involves fewer preparation steps and exhibits good repeatability and potential in large-scale production, which is favorable for thin film technology and other emerging optoelectronic devices.

In our study, two oxide materials, $\mathrm{CuAlO}_{2}$ and $\mathrm{ZnO}$ (crystal structure as shown in Figure 1), were discussed, which are both generally regarded as good candidates for transparent conducting oxides (TCOs), a class of materials with synergistic electrical conductivity and optical transmittance. Due to these unique properties, TCO has been widely used as 


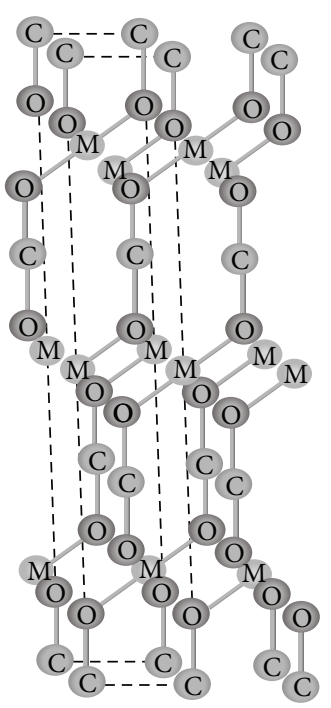

(a)

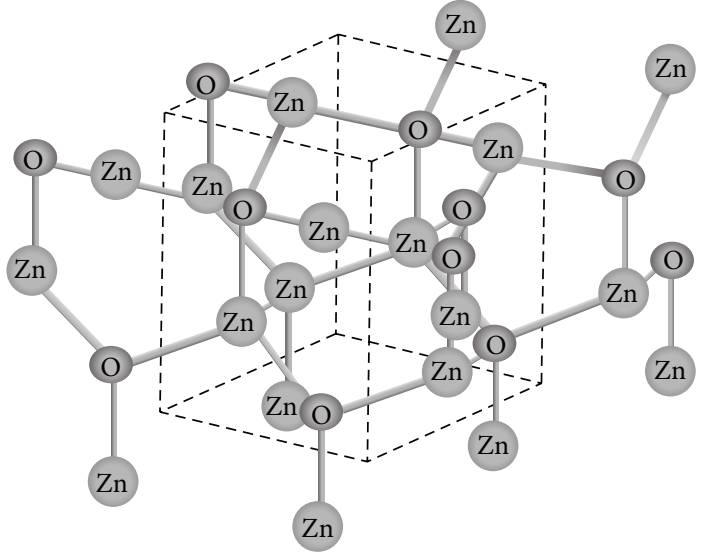

(b)

Figure 1: The delafossite $\mathrm{CMO}_{2}$ (a) and wurtzite $\mathrm{ZnO}$ structures (b).

TABLE 1: Recent advances in oxide materials synthesized by electrohydrodynamic processing.

\begin{tabular}{lccc}
\hline Materials & Morphology & Applications & Reference \\
\hline $\mathrm{AZO} / \mathrm{ITO}$ & Thin film & TCO & {$[26]$} \\
$\mathrm{TiO}_{2}$ & Core-shell spheres & DSSC & {$[27]$} \\
$\mathrm{TiO}_{2}$ & Nanofibers & Photocatalyst/batteries & {$[28]$} \\
$\mathrm{TiO}_{2} / \mathrm{SnO}_{2}$ & Nanofibers & Photocatalyst & {$[29]$} \\
$\mathrm{TiO}_{2} / \mathrm{ZnO}$ & Nanofibers & Photocatalyst & {$[30]$} \\
$\mathrm{NiO}-\mathrm{CdO}$ & Nanofibers & Sensors & {$[31]$} \\
$\mathrm{YSZ}$ & Thin film & SOFCs & {$[32]$} \\
$\mathrm{YSZ}$ & Nanofibers & - & {$[33]$} \\
$\mathrm{SnO}$ & Thin film & Gas sensor & {$[34]$} \\
$\mathrm{ZnO}$ & Thin film & TCO & {$[35]$} \\
$\mathrm{CdO}$ & Nanofibers & TCO & {$[36]$} \\
$\mathrm{CeO}_{2}$ & Nanofibers & Capacitors, catalyst & {$[37]$} \\
$\mathrm{Al}_{2} \mathrm{O}_{3}$ & Nanofibers & - & {$[38]$} \\
$\mathrm{Ga}_{2} \mathrm{O}_{3}$ & Nanofibers & TCO & {$[39]$} \\
$\mathrm{LiCoO}_{2}$ & Wires & Cathode & {$[40]$} \\
$\mathrm{MgO}$ & Nanofibers & Luminescence & {$[41]$} \\
\hline
\end{tabular}

building blocks in architectural applications [9], flat-panel displays including OLEDs, liquid crystal displays, and plasma displays [10], light emitting diodes [11], biosensors [12], and other emerging optoelectronic devices in its form of coatings, thin films, or wires. Most TCOs exhibit unintentional ntype conductivity and degenerate doping could be utilized to achieve a comparable resistivity (in the order of magnitude $\left.10^{-4}-10^{-2} \Omega \cdot \mathrm{cm}\right)$ and carrier density $\left(\sim 10^{20} \mathrm{~cm}^{-3}\right)$ to conventional semiconductors. Unfortunately, there is no active junction device using TCOs to the best of our knowledge, mainly due to the monopolarity of the n-type TCOs [13, 14]. Notwithstanding the lack of research in p-type TCOs compared to n-type ones, the p-type TCOs are essential for constructing the $\mathrm{p}-\mathrm{n}$ functional window in which UV portion of the solar radiation could be absorbed by the electronics, while visible light can be transmitted [15]. The combination of the two types of TCOs not only is an effective approach to improve the optoelectronic performance but also is of great futuristic value to build up the "invisible electronics" [16], such as electronic paper and heads-up displays. $\mathrm{CuAlO}_{2}$ is the first reported p-type TCO without intentional doping by Kawazoe et al. [17] in 1997. The most distinguished feature for this material is its anisotropic electrical conductivity [18] stemming from the delafossite structure (Figure 1(a)) and the linearly coordinated copper atoms. However, the development of this material has lagged far behind that of n-type TCOs, mainly due to two reasons. The first reason is its inherently low conductivity and difficulty in degenerate doping. Even though there have been a few reports on using divalent dopants such as $\mathrm{Mg}$ and $\mathrm{Ca}$ [19-21] to increase the hole concentration, the dominant $\mathrm{O}_{2} \mathrm{p}$ states underlying the conduction band may strongly localize the extrinsic hole carriers [22]. The second reason lies in the fact that the conductivity highly depends on processing parameters and usually a wide range of optical bandgap values are reported from different synthesizing methods. There have been few reports $[23,24]$ on $\mathrm{CuAlO}_{2}$ via electrohydrodynamic processing, which would be a reproducible and cost-effective method for fabricating thin films and fibers. $\mathrm{ZnO}$, on the other hand, has been long used for n-type optoelectronic devices for decades. As shown in Figure 1, $\mathrm{ZnO}$ with wurtzite structure possesses large band gap and large portion open space, which is suitable for doping. However, it encounters the similar processing and doping issues as a p-type semiconductor mainly because of the self-compensation from native donor defects $\left(\mathrm{Zn}_{i}\right.$ and $\left.\mathrm{V}_{\mathrm{O}}\right)$ [25]. By using the electrospray technique, we selected lithium (acceptor, A) and aluminum (donor, D) as the codopants to achieve the improvement in conductivity and the mitigation of lattice distortion simultaneously. The 


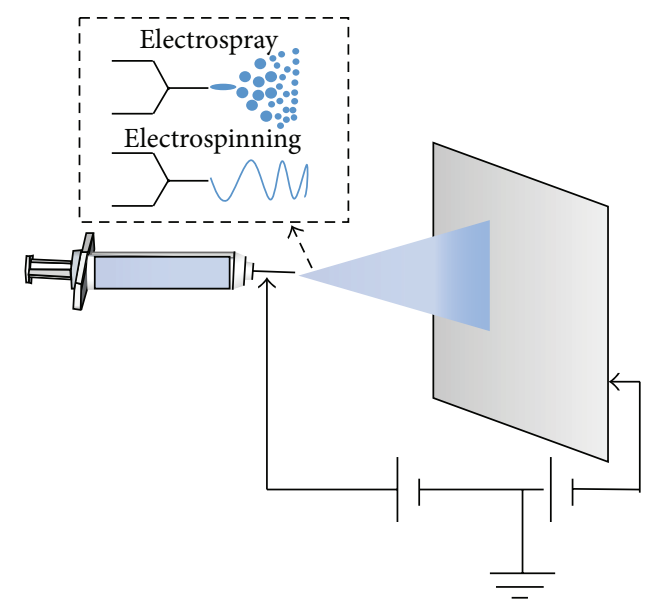

FIGURE 2: A general setup of electrohydrodynamic processing with droplets or a single fiber exiting the capillary under the forward bias electrical field.

enhanced dopant solubility in the present $\mathrm{ZnO}$ may shed new light on constructing homojunction devices.

\section{Electrohydrodynamic Synthesis of p-Type $\mathrm{CuAlO}_{2}$}

2.1. Experimental Setup. A combination of electrohydrodynamic jet forming and modified sol-gel method was developed to synthesize $\mathrm{CuAlO}_{2}$ ceramics directly from chemical solutions. Stoichiometric $\mathrm{Cu}\left(\mathrm{NO}_{3}\right)_{2} \cdot 3 \mathrm{H}_{2} \mathrm{O}$ (Sigma-Aldrich, puriss. p.a.), $\mathrm{Al}\left(\mathrm{NO}_{3}\right)_{3} \cdot 9 \mathrm{H}_{2} \mathrm{O}$ (Sigma-Aldrich, ACS reagent), and dopant ions $\left(\mathrm{Y}^{3+}\right.$ and $\left.\mathrm{Ln}^{3+}\right)$ in nitrate form were used as the starting agents dissolved in corresponding solvents. In the case of $\mathrm{CuAlO}_{2}$ thin film fabrication through electrospray, nonaqueous precursor (1:1 ethylene glycol/ethanol, $0.5 \mathrm{M}$ ) was prepared and stirred at $70^{\circ} \mathrm{C}$. Then a polyacrylamide route [42] was used in which acrylamide, N,N bis-methylene acrylamide, and ammonium persulfate were added to the solution one by one. The as-formed polyacrylamide gel could provide a diphasic medium to immobilize the precursor solution and render the feasible low-temperature synthesis for $\mathrm{CuAlO}_{2}$ formation. For electrospinning precursor, the above metal salts were firstly dissolved in methanol and then mixed with citric acid solution. Polymeric agent Polyvinylpyrrolidone (PVP) (Sigma-Aldrich, average mol. wt. 40,000) was further added to the gel in the attempt to acquire suitable viscoelasticity for electrospinning. As shown in Figure 2, a home-built electrohydrodynamic jet forming setup utilizing DC high voltage was used for both electrospray $(5-8 \mathrm{kV}, 0.1$ and $0.5 \mathrm{~mL} / \mathrm{h})$ and electrospinning $(15-18 \mathrm{kV}$, $1 \mathrm{~mL} / \mathrm{h})$. The resultant jet-formed products deposited onto quartz substrates went through heat treatment at various temperatures to investigate the phase evolution.

\subsection{Microstructure and Crystal Phase Evolution through Elec-} trohydrodynamic Processing and Successive Heat Treatment. The microstructure through electrohydrodynamic processing could be highly tailored into various forms, while the crystallite size could remain at the submicron level. The key challenges to electrospray and electrospinning are to acquire dense thin films and uniform fiber dimensions through a stable electrohydrodynamic jetting. Due to the inherent complexity of the electrohydrodynamic jet forming and propulsion, the parameter optimization is still on the experimental basis and solid theoretical models that encompass pertinent variables have yet to be built. We herein show the examples of several processing parameters influencing microstructure evolution. Figure 3 is a brief summary of different microstructures generated under different spray rate, electrical field, and working time. The as-spray film exhibited amorphous topography consisting of overlapping monodispersed droplets. Upon heat treatment $\left(800^{\circ} \mathrm{C}\right.$ in argon) and the decomposition of organics, discrete spherical particles were formed on the substrate, and at an optimum electrospray condition shown in Figure 3(e) dense films of $\sim 4 \mu \mathrm{m}$ thickness were obtained (also confirmed from cross section view from Figure 3(f)). The electrical field required for electrospinning is higher due to significant dielectric constant increase in the viscous precursors tuned by high molecular weight PVP. The jet formed at the capillary would be a single cylindrical fiber with elongation and thinning effects, as long as a suitable electrohydrodynamic condition could be met. At the low voltage applied under $2000 \mathrm{~V} / \mathrm{cm}$, the microstructure of the as-spun fibers prior to thermal treatment is a mixture of droplets and fibers, indicating a transitional electrohydrodynamic jet forming deviated from electrostatic balance in which the conical jet is unstable with charged droplet encapsulated into the jet stream. Even though this special microstructure is of great importance in some applications such as drug delivery, the mixed structure cannot meet the requirements of producing uniform and interconnected fibrous ceramic coatings for optoelectronic applications. By using an electrical field of $2000 \mathrm{~V} / \mathrm{cm}$, uniform fibers could be formed and the self-sustained network could survive after thermal treatment, during which polymeric fibers were transformed into polycrystalline $\mathrm{CuAlO}_{2}$. The enlarged micrograph of Figure 4(f) shows one single submicron fibers with fine polycrystalline grains.

Due to the narrow thermodynamic window of delafossite $\mathrm{CuAlO}_{2}$ phase, various annealing temperatures were examined on both thin film and fibrous samples. According to the XRD results shown in Figure 5 , at $500^{\circ} \mathrm{C}$, only $\mathrm{CuO}$ phase was present due to the thermal decomposition of copper nitrate. With the help of acrylamide gelification, the crystallinity significantly improved after annealing in argon at $800^{\circ} \mathrm{C}$, whereas this is not the case when no acrylamide was involved even at a higher annealing temperature. There was no intermediate phase such as spinel $\mathrm{CuAl}_{2} \mathrm{O}_{4}$ identified. For the case of the precursor used for electrospinning, which is simply a citrate-nitrate system, the spinel $\mathrm{CuAlO}_{4}$ was formed by the following reaction: $\mathrm{CuO}+\mathrm{Al}_{2} \mathrm{O}_{3} \rightarrow \mathrm{CuAl}_{2} \mathrm{O}_{4}$ at $900^{\circ} \mathrm{C}$. According to the phase equilibria in the system of $\mathrm{Cu}_{2} \mathrm{O}-\mathrm{CuO}-\mathrm{Al}_{2} \mathrm{O}_{3}$ [43], $\mathrm{CuAlO}_{4}$ and $\mathrm{CuO}$ phases containing $\mathrm{Cu}(\mathrm{II})$ are stable at the temperature range of 625 to $1000^{\circ} \mathrm{C}$, whereas the delafossite $\mathrm{CuAlO}_{2}$ is a metastable phase below $1000^{\circ} \mathrm{C}$, which could be decomposed to $\mathrm{CuAlO}_{4}$. Single delafossite phase $\left(\mathrm{CuAlO}_{2}\right.$, rhombohedral, PDF\#35-1401) was 


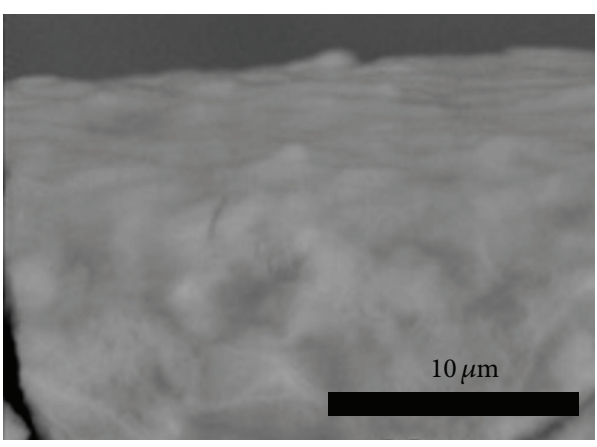

(a)

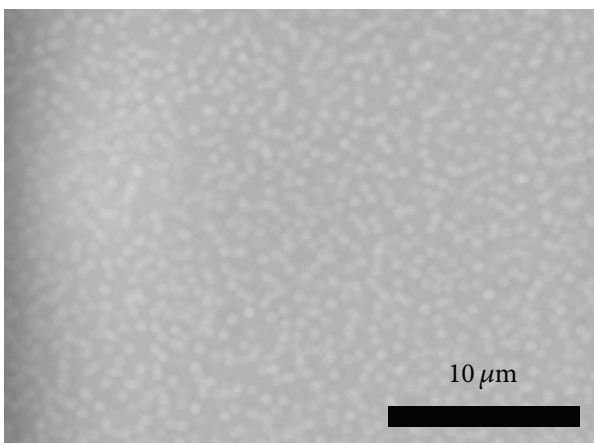

(c)

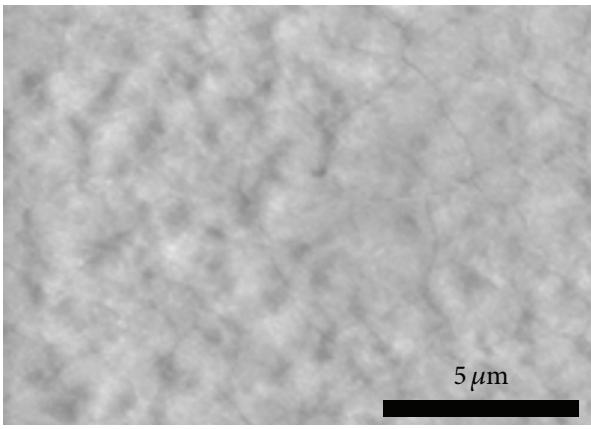

(e)

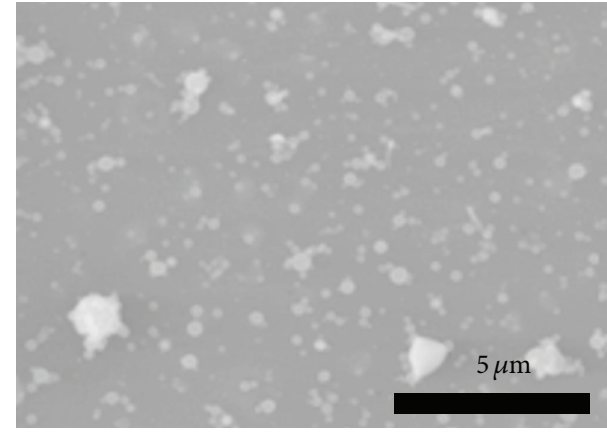

(b)

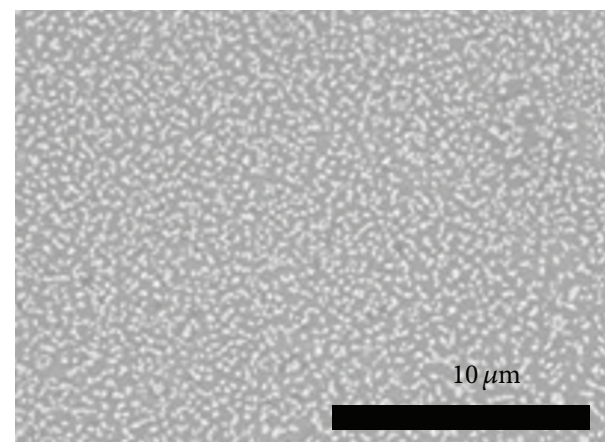

(d)

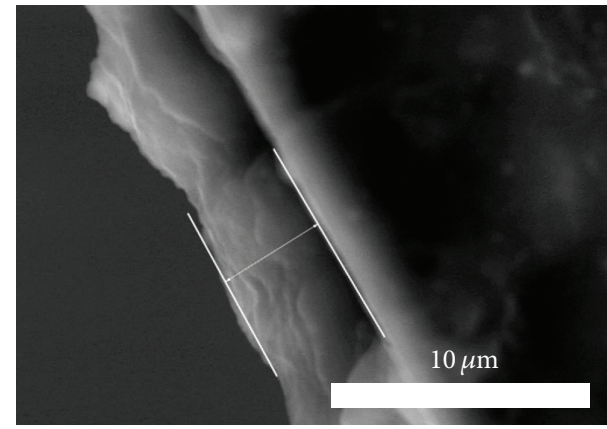

(f)

FIgURE 3: SEM microstructures of electrosprayed $\mathrm{CuAlO}_{2}$ : (a) as-sprayed without heat treatment from tilt view; (b) spray rate, $0.1 \mathrm{~mL} / \mathrm{h}$, electrical field, $500 \mathrm{~V} / \mathrm{cm}$, and spray time, $5 \mathrm{~min}$; (c) spray rate, $0.5 \mathrm{~mL} / \mathrm{h}$, electrical field, $500 \mathrm{~V} / \mathrm{cm}$, and spray time, $10 \mathrm{~min}$; (d) spray rate, $0.5 \mathrm{~mL} / \mathrm{h}$, electrical field, $1000 \mathrm{~V} / \mathrm{cm}$, and spray time, $15 \mathrm{~min}$; (e) spray rate, $0.5 \mathrm{~mL} / \mathrm{h}$, electrical field, $1000 \mathrm{~V} / \mathrm{cm}$, and spray time, $30 \mathrm{~min}$, with cross section image shown in (f).

formed in its stable form after annealing at $1100^{\circ} \mathrm{C}$ for $3 \mathrm{hr}$. The reaction formula is as follows:

$$
\mathrm{CuO}+\mathrm{CuAl}_{2} \mathrm{O}_{4} \longleftrightarrow 2 \mathrm{CuAlO}_{2}+\left(\frac{1}{2}\right) \mathrm{O}_{2}
$$

2.3. Electrical and Optical Characterizations of $\mathrm{CuAlO}_{2}$ Thin Films and Nanofibers. Due to the poor p-type conductivity of delafossite $\mathrm{CuAlO}_{2}$, there have been many attempts to improve the electrical conductivity, such as divalent doping [19-21] and nitrogen doping [44]. Trivalent dopant in substitution of $\mathrm{Al}$ site has become a new experimental interest in recent years. Based on some calculation results [22], the substitution doping is predicted to increase the density of states at the top of the valence band. Additionally, the change of M-O covalency could lead to a decrease of $\mathrm{O}$ valance charge in the $\mathrm{Cu}-\mathrm{O}$-Al unit, which finally mediates $\mathrm{Cu}$ d states and an improved conductivity would be expected. Inspired by $\mathrm{CuYO}_{2}$ compounds and the potential alloying effects, $\mathrm{Y}$ ion was chosen to partially substitute $\mathrm{Al}$ site. Figure 6 depicts three typical electrical characterization methods. All the samples exhibited semiconducting conductivity with a monotonically reduced thermal activation energy as the yttrium doping increased. Even though the various hopping mechanisms in $\mathrm{CuAlO}_{2}$ have been reported, at the measured temperature range, the linearity indicted a thermal activation type hopping. Recalling the change of optical direct band gap shown in Figure 6(c), the introduction of yttrium modified 


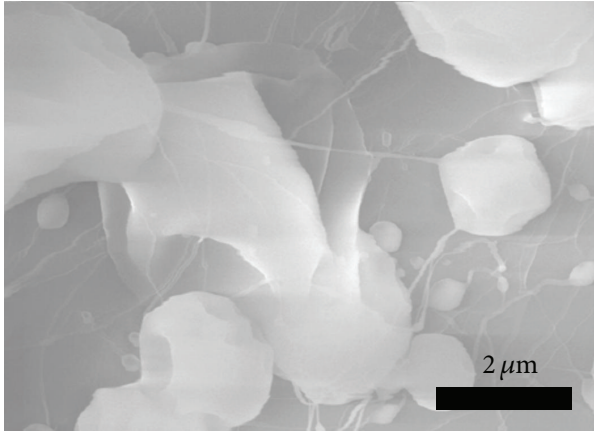

(a)

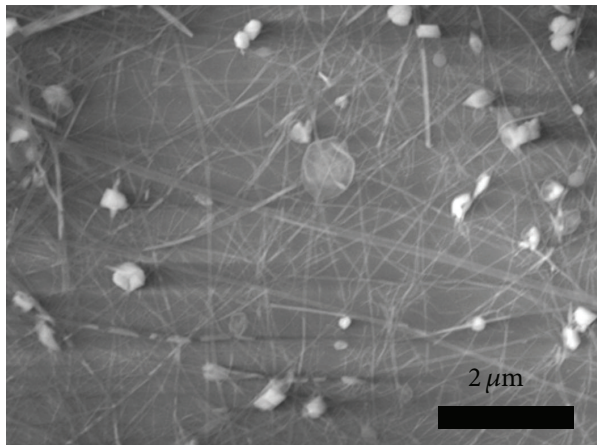

(c)

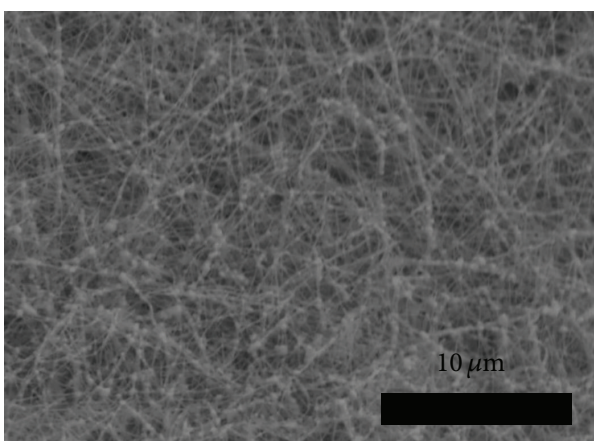

(e)

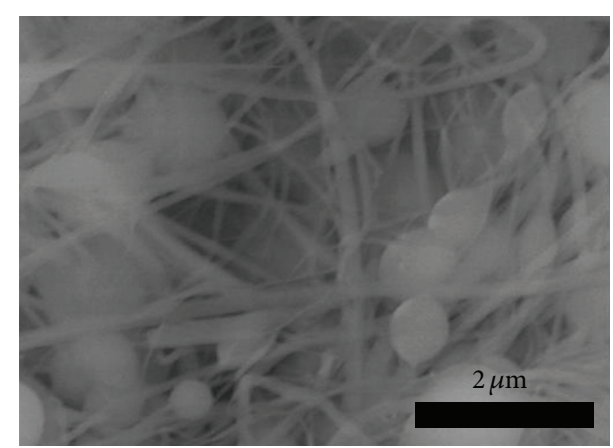

(b)

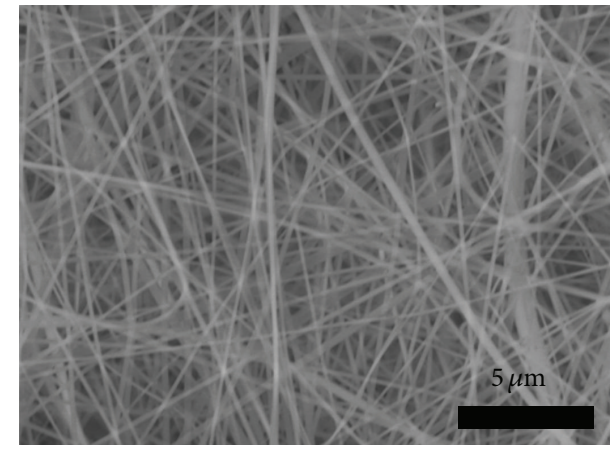

(d)

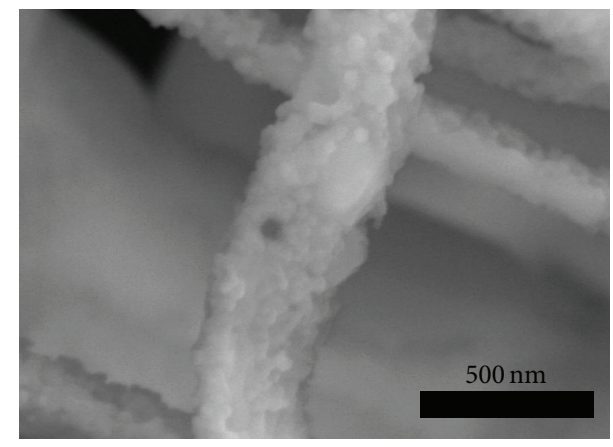

(f)

Figure 4: $\mathrm{CuAlO}_{2}$ nanofibers fabricated through electrospinning: (a) as-spun, $500 \mathrm{~V} / \mathrm{cm}$; (b) as-spun, $1000 \mathrm{~V} / \mathrm{cm}$; (c) as-spun, $1500 \mathrm{~V} / \mathrm{cm}$; (d) as-spun, $2000 \mathrm{~V} / \mathrm{cm}$; (e) and (f) fully crystallized, annealed at $1100^{\circ} \mathrm{C}$.

the band edge and might change $\mathrm{Cu}-\mathrm{O}$ confinement to a degree that the excitons underlying the valence band became more delocalized, thus decreasing the activation energy when thermally excited from VB to CB. The overall resistivity obtained from calculating the $V-I$ slope shows a decrease from $689 \Omega \cdot \mathrm{cm}$ to $580 \Omega \cdot \mathrm{cm}$ as the Y concentration goes up from 0 to 5 at.\%. Even though the improvement is very small, the consistency lying within the band gap, resistivity, and thermal activation energy might indicate that the substitutional trivalent doping with orderly alloying effects could be useful for a better understanding of the doping mechanisms compared to divalent doping, which may increase the charge complexity and obscure some underlying phenomena.

The fate of electrohydrodynamic is its simplicity in producing nanostructured coatings or thin films with high transparency in the visible region, which is highly favored by transparent conducting oxides. The samples could be easily deposited onto glass or quartz substrates due to the strong attractive force between charged jet and grounded collector. After annealing, the polycrystalline structure could be formed. The sample from electrospray (shown in Figure 3(f)) has a lowered transmittance in the visible region in Figure 7. The dense polycrystalline delafossite anisotropic structure could enhance the beam scattering, thus decreasing the transmittance. On the other hand, the electrospun sample with a stacking thickness of $\sim 20 \mu \mathrm{m}$ [6] has a porous structure and due to the stacking of fiber mats and reduced contact area, the actual coating thickness absorbing the visible light could not be high. Therefore, the electrospun sample exhibited higher transmittance compared to the electrospray coating.

Another striking fact about $\mathrm{CuAlO}_{2}$ is the room temperature near-band-edge emission in the UV/blue region, 


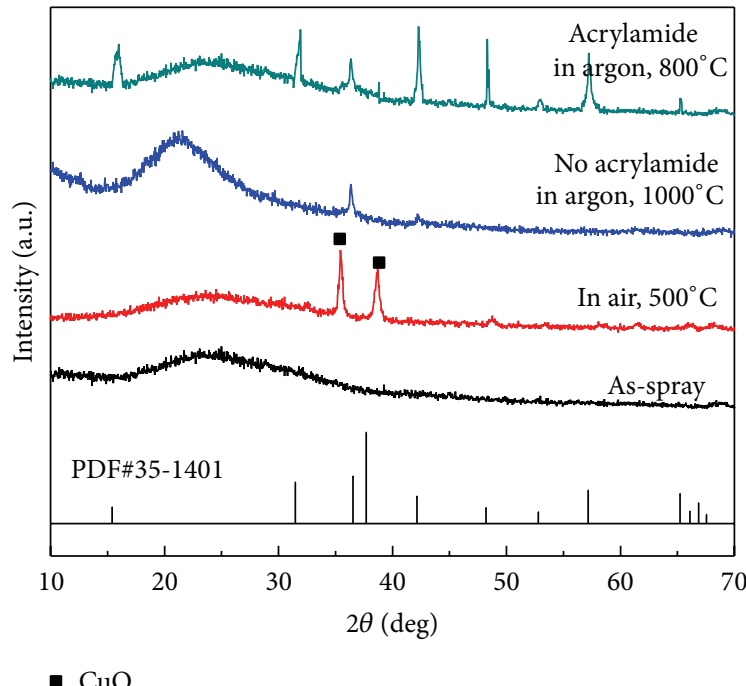

(a)

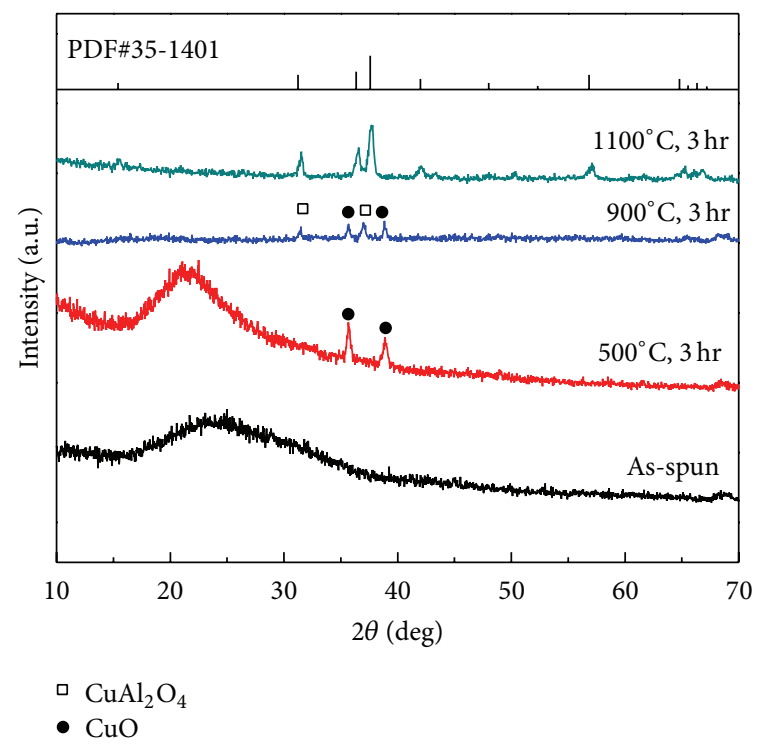

(b)

FIGURE 5: The XRD patterns of the electrospray (a) and electrospinning (b) products with respect to different heat treatment conditions.

making it a promising luminescent candidate. In delafossite $\mathrm{CuAlO}_{2}, \mathrm{Cu}-\mathrm{O}$ bonds in $\mathrm{O}-\mathrm{Cu}-\mathrm{O}$ dumbbell layers determine the electronic structure near the band gap and lead to strong localization of excitons in the $x-y$ plane as well as larger binding energy. Since the binding energy exceeded the room temperature thermal energy $(k T \approx 0.025 \mathrm{eV})$, room temperature PL emissions were presented. Our recent study [24] also showed that this near-band-edge emission might be also closely associated with $\mathrm{Cu} 3 \mathrm{~d} / 4 \mathrm{p}$ hybridization as a result of trivalent site mediation. The electrohydrodynamic processing could enable us to deposit $\mathrm{CuAlO}_{2}$ precursors with different doping species and concentration and obtain the transparent sample ready for optical characterization. Figure 8 includes three samples with different trivalent site configurations. Distinct peak shift is identified, showing different Stokes shifts of $\mathrm{d}\left(3 \mathrm{~d}_{z}^{2}-4 \mathrm{~s}\right) \rightarrow 3 \mathrm{~d}^{9} 4 \mathrm{p}^{1}$ transition. However, the trend showing here is in contradiction with the claim that this Stokes shift decreases as the size of the trivalent metal atom reduces [45]. The nanostructure fibers or thin films on the other hand could also contribute to the Stokes shift, usually a blue shift in the luminescence spectra. Therefore, the modification of the morphology and dimension of those nanostructures could generate tunable luminescence.

While most researchers focus on the electrical properties of $\mathrm{CuAlO}_{2}$ as a p-type transparent conducting oxide, there are few reports in viewing $\mathrm{CuAlO}_{2}$ as a potential phosphor material. In addition, with the development of field emission display and other flat display technologies, new generation of phosphors with good luminescence, conductivity, and stability is required. $\mathrm{CuAlO}_{2}$ could be a promising host material in which $\mathrm{Al}$ site could be substituted with various trivalent rare earth dopants, without changing the hole transport within $\mathrm{Cu}^{+}$plane [46]. Since the main conduction path in delafossite crystals is close-packed $\mathrm{Cu}^{+}$ layers [18], the electrical properties could be sustained in addition to photoluminescence properties. Conventional solid-state synthesis of $\mathrm{CuAlO}_{2}$ powders or thin films requires high temperature sintering and repeated thermal treatments. We hereby prepared $\mathrm{CuAlO}_{2}$ fibers via a costeffective electrospinning method. The wire-like $\mathrm{CuAlO}_{2}$ nanostructures possess higher surface area and sintering activity, which could lower the annealing temperature. Additionally, the one-dimensional material may also present extraordinary effectiveness in light emitting and transparent conducting [47-49]. $\mathrm{Eu}^{3+}$ cation was chosen as the emission activator and intense red emission from $\mathrm{f}-\mathrm{f}$ transition of $\mathrm{Eu}^{3+}$ was identified. Eu ${ }^{3+}$ activator center was successfully doped into $\mathrm{Al}^{3+}$ site and this delafossite-type material could be used as potential host for luminescence application.

\section{Electrospray Synthesis of Codoped ZnO}

3.1. Experimental Setup and Thin Film Topography. The electrosprayed $\mathrm{ZnO}$ with codopants could be synthesized from a similar chemical solution method, in which $\mathrm{Zn}\left(\mathrm{CH}_{3} \mathrm{COO}\right)_{2} \cdot 2 \mathrm{H}_{2} \mathrm{O}$ (Fisher Scientific), $\mathrm{AlN}_{3} \mathrm{O}_{9} \cdot 9 \mathrm{H}_{2} \mathrm{O}$ ( $\geq 98 \%$, Sigma-Aldrich), and $\mathrm{CLi}_{2} \mathrm{O}_{3}$ ( $\geq 99 \%$, Sigma-Aldrich) were dissolved in 9:1 v/v of Diethylene Glycol $(\geq 99 \%$ BioUltra $\mathrm{C}_{4} \mathrm{H}_{10} \mathrm{O}_{3}$, Sigma-Aldrich) and deionized water solution. For electrospray, a deposit rate of $0.06 \mathrm{~mL} / \mathrm{hr}$ with applied voltage of $20.0 \mathrm{kV}$ and $15 \mathrm{~cm}$ of deposit distance were used to deposit nanodroplets onto preheated substrate $(93 \pm$ $5^{\circ} \mathrm{C}$ ) for 60 minutes. The as-sprayed substrates were annealed in air at $500^{\circ} \mathrm{C}$ for $5 \mathrm{hr}$. The crystallized $\mathrm{ZnO}$ thin films after calcination have an average thickness of $\sim 160 \mathrm{~nm}$.

3.2. Effects of Codoping on Morphology and Electrical Properties. The aim of using codopants is to mitigate lattice 


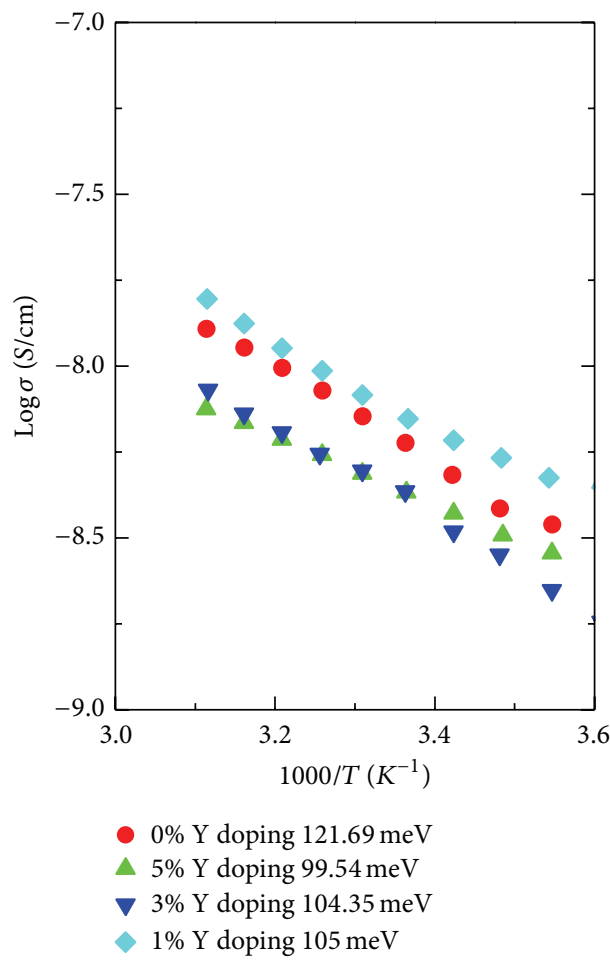

(a)

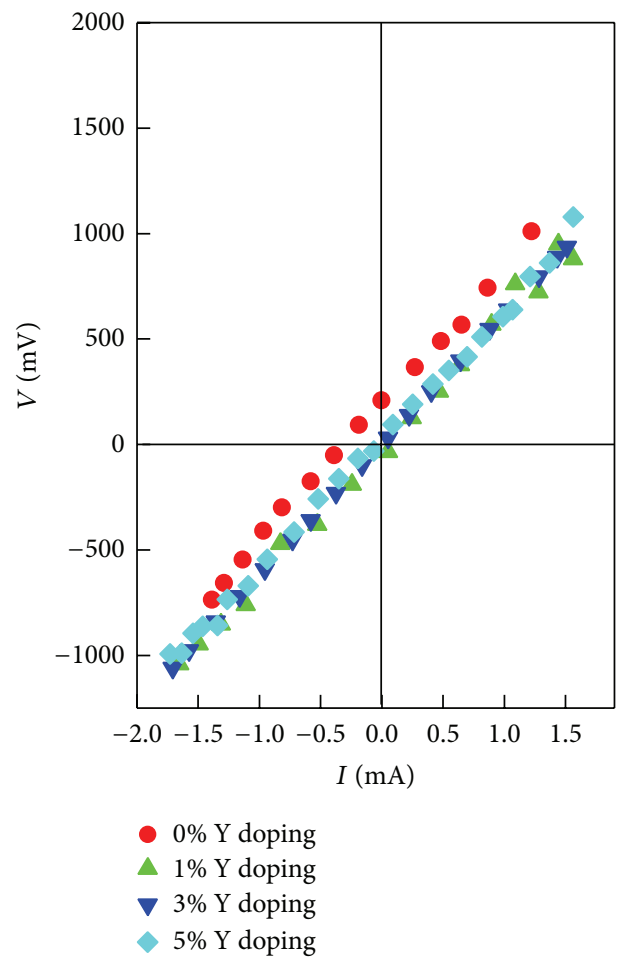

(b)

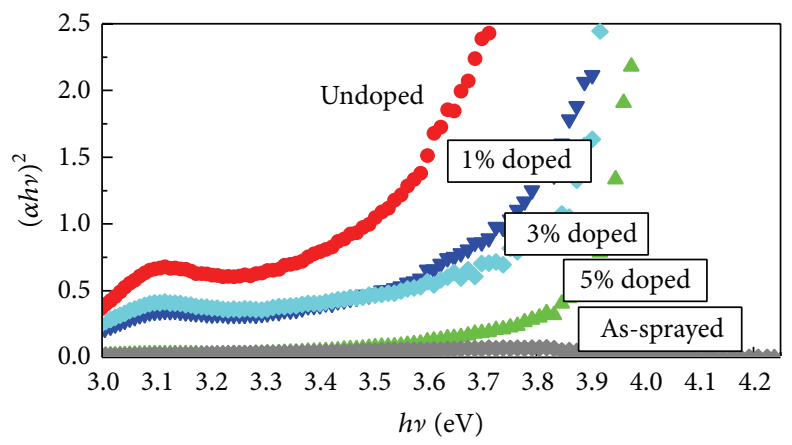

(c)

FIGURE 6: Summary of electrical properties of electrosprayed $\mathrm{CuAlO}_{2}$ thin films. (a) Temperature-dependent DC conductivity. (b) Four-probe $V-I$ curve. (c) Tauc plot extrapolated from UV diffuse reflectance.

distortion introduced by aluminum ions. From XRD shown in Figure 9, the degree of crystallinity decreased with the increase of $\mathrm{Al}$ concentration as shown in FWHM (002). The average introduced stress from the difference radii between the host and dopant restrained growth process. Moreover, the substitute defect was formed and increased a compressive stress that induced a degenerated issue resulting in small grain size. In contrast, after incorporating Li ions, the FWHM rarely changed over \% Al range of dopant resulting in crystallite size remaining almost constant, indicating a stress relaxation and better crystallization took place. Less stress was introduced in the $3 \% \mathrm{Li}$-doped sample due to the smaller difference of radii between $\mathrm{Zn}$ and Li. By employing the Double-Voigt approach based on the diffraction patterns (002), the strain $\mathrm{e}_{0}$ for undoped $\mathrm{ZnO}$ is $\sim 0.0036$ and it increased slightly to $\sim 0.0046$ in the $3 \% \mathrm{Li}$-doped $\mathrm{ZnO}$ thin film. Therefore, the lattice distortion in $\mathrm{Li}$ codoped $\mathrm{ZnO}$ samples was kept constant as \% $\mathrm{Al}$ increases indicating that the dopant solubility improved by codoping mechanism. However, the lattice distortion increased when $\mathrm{Al}$ concentration increased due to the small size of $\mathrm{Al}$ and less contraction at $c$-axis when being substituted on the $\mathrm{Zn}$ site.

The AFM in Figure 10 reveals the general topography of samples with different doping configurations. Undoped and Li-doped $\mathrm{ZnO}$ samples exhibited larger grain size compared to other doped and codoped $\mathrm{ZnO}$ samples. At 3.0\% Al-doped $\mathrm{ZnO}$ has a large size difference compared to host $\left(\mathrm{Zn}^{2+}\right)$, so the stress caused a degenerated issue resulting in small grain size being observed which was consistent with crystallite size studies. It is noteworthy that introducing of the second $\mathrm{Li}$ dopant could smooth the thin film surface and a significant drop in RMS was also observed in Table 2. This improvement 
TABLE 2: Roughness evolution observed by AFM from undoped and codoped $\mathrm{ZnO}$ samples.

\begin{tabular}{lccc}
\hline Sample detail & $\begin{array}{c}\text { Average } \\
\text { roughness } \\
(\mathrm{nm})\end{array}$ & $\begin{array}{c}\text { RMS } \\
\text { roughness } \\
(\mathrm{nm})\end{array}$ & Skewness \\
\hline Undoped $\mathrm{ZnO}$ & 9.1591 & 11.5280 & 0.3712 \\
3\% Li-doped $\mathrm{ZnO}$ & 5.3446 & 6.5457 & -0.2644 \\
3\% Al-doped $\mathrm{ZnO}$ & 33.6361 & 41.592 & -0.1874 \\
3-3\% Al-Li codoped $\mathrm{ZnO}$ & 13.6971 & 16.7416 & 0.0468 \\
\hline
\end{tabular}

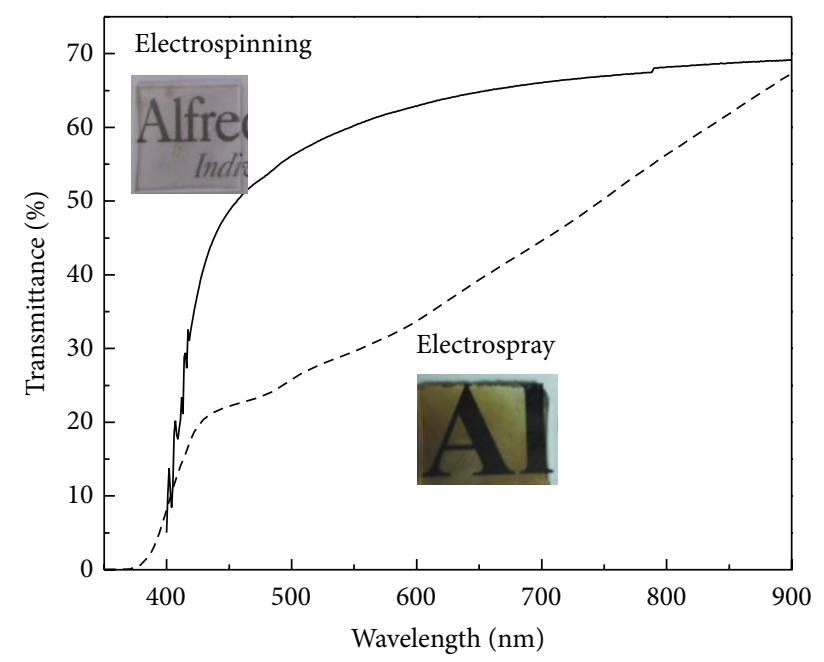

FIgURE 7: Transmittance spectra of $\mathrm{CuAlO}_{2}$ coatings from both electrospray and electrospinning.

in thin film quality is also considered to be associated with the relaxation of lattice strains allowing growth process. The $\mathrm{Li}$ ions increased dopant solubility and accommodated $\mathrm{Al}$ to localize with minimal stress.

A visible transmittance of $85 \%-90 \%$ could be achieved in the electrosprayed samples as shown in Figure 11. As $\mathrm{Al}^{3+}$ went up, transmittance in visible range increased because there was no segregation of $\mathrm{Al}$ at grain boundary and $\mathrm{Al}_{i}$ defect as scattering centers. Another plausible reason lies in the fact that $\mathrm{AlO}_{6}$ octahedron was reported [50] to decrease the surface roughness, which could also help increase the in-line transmittance. Li promoted solubility and facilitated grain growth, which improved the transmittance by mitigating grain boundary effect. A presence of $\mathrm{Li}$ in codoped $\mathrm{ZnO}$ showed higher transparency suggesting that there was no interstitial $\mathrm{Li}\left(\mathrm{Li}_{i}\right)$ defect or near-bandedge defect to increase light absorption in visible range meaning that the defect complex $\left(\mathrm{Li}_{\mathrm{Zn}}-\mathrm{Li}_{i}\right)$ was formed. Therefore, the reduction of charge effective carrier was observed.

The Burstein-Moss effect or band gap widening was observed in all doped samples due to the fact that the excess charge carriers by dopants were blocked at the lowest part of the conduction band. The double occupation is prohibited according to Pauli exclusive principle. However, the band gap energy of Li codoped samples was maintained because the

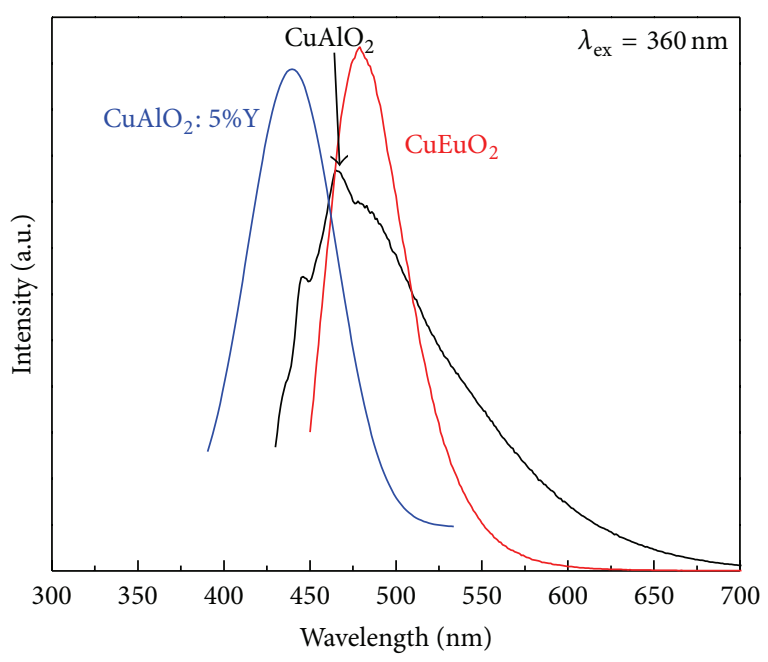

Figure 8: Room temperature photoluminescence of 3 delafossite samples synthesized via electrospinning.

defect complex was formed to reduce ionic defects and thus electronic defects were decreased.

The electrical properties results in Table 3 reveal that all Li-doped $\mathrm{ZnO}$ films showed p-type semiconductor meaning that hole carriers were dominated in an electrical conductivity. The resistivity and the resistance of as-annealed films by Hall-effect measurement and in-line 4-point probe measurement showed the same tendency. A 1.5-3\% (Al, Li) codoped $\mathrm{ZnO}$ film showed the lowest resistance, resistivity, and sheet resistivity of the film of $9.6 \mathrm{Ohm}, 9.59 \mathrm{Ohm} \cdot \mathrm{cm}$, and $29.5 \mathrm{Ohm} / \mathrm{cm}^{2}$, respectively. The carrier mobility was $9.51 \mathrm{~cm}^{2} /$ Vs and the carrier density was $6.85 \times 10^{16} \mathrm{~cm}^{-3}$. This phenomenon can also be explained in terms of mobility effect which was improved by enhancing dopant solubility at the optimal acceptor-to-donor ratio of $2: 1$. The highest solubility indicated by the lowest lattice distortion suggested that the incorporation of acceptor improved by forming acceptor-donor (A-D-A) defect complex resulting in the electronic band structure being tailored to enhance the efficiency of charge carrier transportation [51]. This A-DA defect complex shifted acceptor and donor energy levels close to the valence and conduction bands, respectively, by electrostatic force. These periodical A-D-A defect complexes or trimmers induced a short-range dipole-like scattering mechanism resulting in a decrease of mobility scattering [52]. Moreover, the grain boundary was diminished as shown in SEM image, so the grain boundary scattering exhibited the smallest effect compared to other doped $\mathrm{ZnO}$-based films. The lowest resistivity was observed in the $1.5-3 \% \mathrm{Al}-$ $\mathrm{Li}$ codoped $\mathrm{ZnO}$ due to the increased hole mobility in order to compensate for the loss of carrier from a native defect or a defect cluster $\left(\mathrm{Li}_{\mathrm{Zn}_{\mathrm{n}}}-\mathrm{Li}_{i}\right)$.

The higher resistivity and low mobility were observed in $3 \% \mathrm{Li}$ monodoped $\mathrm{ZnO}$ film due to the fact that the mobility was low because p-type dopant preferred to localize at deep level of acceptor. In addition, the energy band structure of single doped $\mathrm{ZnO}$ was higher than that of the codoped one [51]. At 3-3\% (Al-Li) codoped $\mathrm{ZnO}$ due to the hole carrier density was reduced to more than $50 \%$ compared to $3 \%$ 
TABLE 3: General electrical properties measured from Li-doped and $\mathrm{Li}-\mathrm{Al}$ codoped $\mathrm{ZnO}$ samples.

\begin{tabular}{|c|c|c|c|c|c|c|}
\hline Sample detail & $\begin{array}{c}\text { Resistance } \\
(\mathrm{Ohm})\end{array}$ & $\begin{array}{l}\text { Resistivity } \\
(\mathrm{Ohm} \cdot \mathrm{cm})\end{array}$ & $\begin{array}{l}\text { Mobility } \\
\left(\mathrm{cm}^{2} / \mathrm{Vs}\right)\end{array}$ & $\begin{array}{c}\text { Carrier density } \\
\left(\mathrm{cm}^{-3}\right)\end{array}$ & $\begin{array}{c}\text { Sheet resistance } \\
\left(\mathrm{Ohm} / \mathrm{cm}^{2}\right)\end{array}$ & Type of carriers \\
\hline 3\% Li-doped $\mathrm{ZnO}$ & 15.07 & 15.06 & 0.918 & $4.52 E+17$ & $3.18 E+03$ & Holes \\
\hline 1.5-3\% Al-Li-doped ZnO & 9.60 & 9.59 & 9.51 & $6.85 E+16$ & $2.95 E+01$ & Holes \\
\hline 3-3\% Al-Li-doped $\mathrm{ZnO}$ & 19.05 & 19.05 & 1.54 & $2.13 E+17$ & $3.11 E+03$ & Holes \\
\hline
\end{tabular}

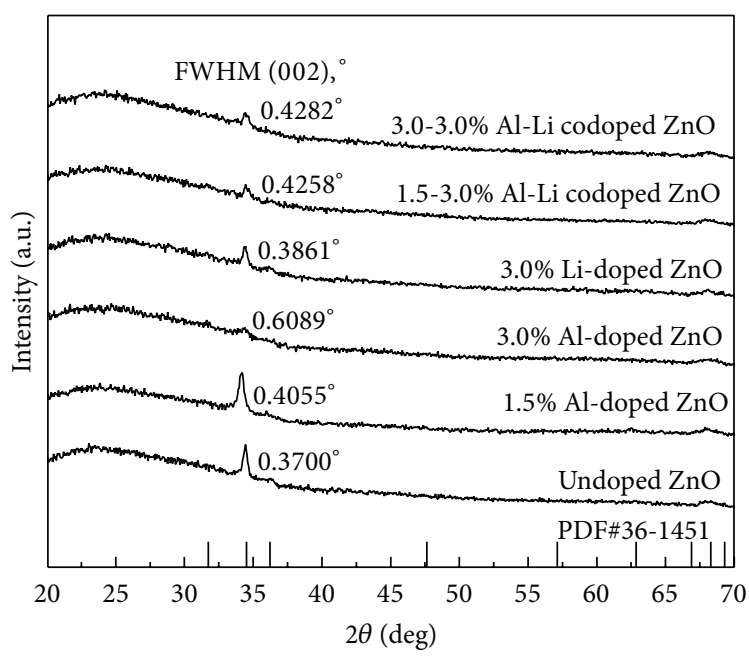

(a)

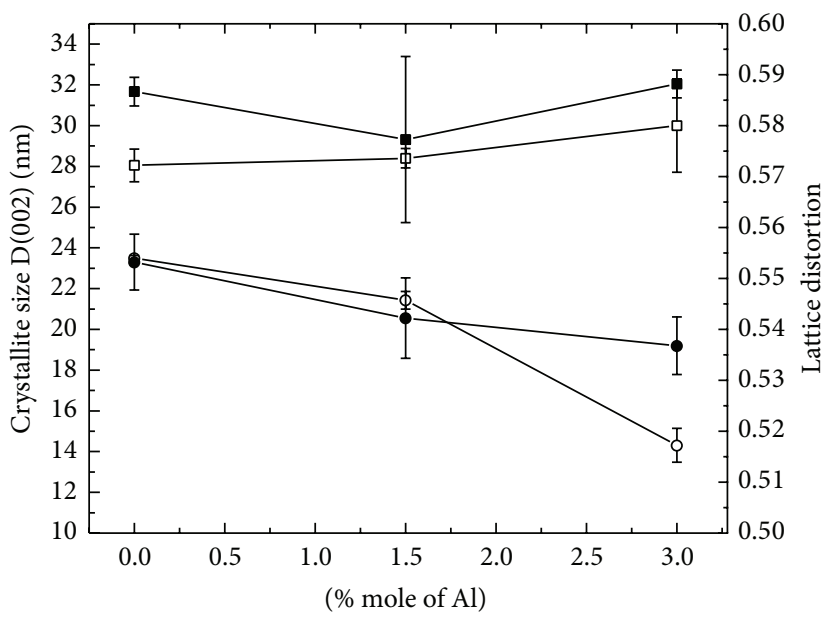

-०- $\mathrm{D}(002)$ without $\mathrm{Li} \quad-\square-$ Lattice distortion without $\mathrm{Li}$

-• $\mathrm{D}(002)$ with $3 \% \mathrm{Li} \quad$ - - Lattice distortion with $3 \% \mathrm{Li}$

(b)

FIGURE 9: XRD patterns of $\mathrm{ZnO}$ with the summarized crystallite information from Rietveld refinements.
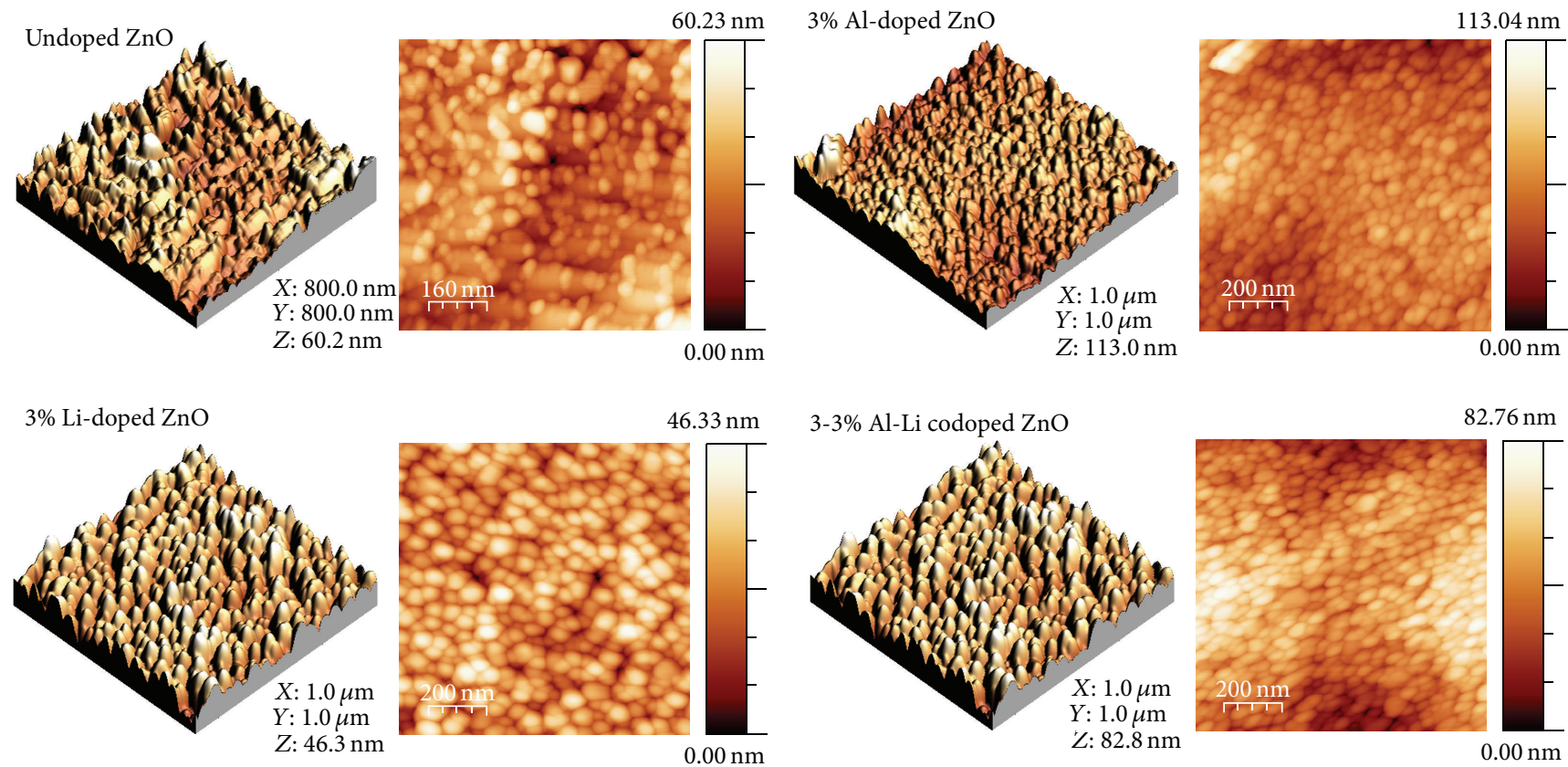

FIgURE 10: AFM images of $\mathrm{ZnO}$-based TCO.

Li-doped $\mathrm{ZnO}$. Al doping at high concentration could form substitute defect $\left(\mathrm{Al}_{\mathrm{Zn}}\right)$ and induce the population of intrinsic defect $\left(\mathrm{Zn}_{i}\right)$, which was in agreement with lattice distortion studies in Figure 9. Consequently, the higher resistivity ptype $\mathrm{ZnO}$ film could be found.

\section{Emerging Applications of Classical p-Type TCOs}

As mentioned above, the versatile nature of electrohydrodynamic processing could open new doors for new materials 


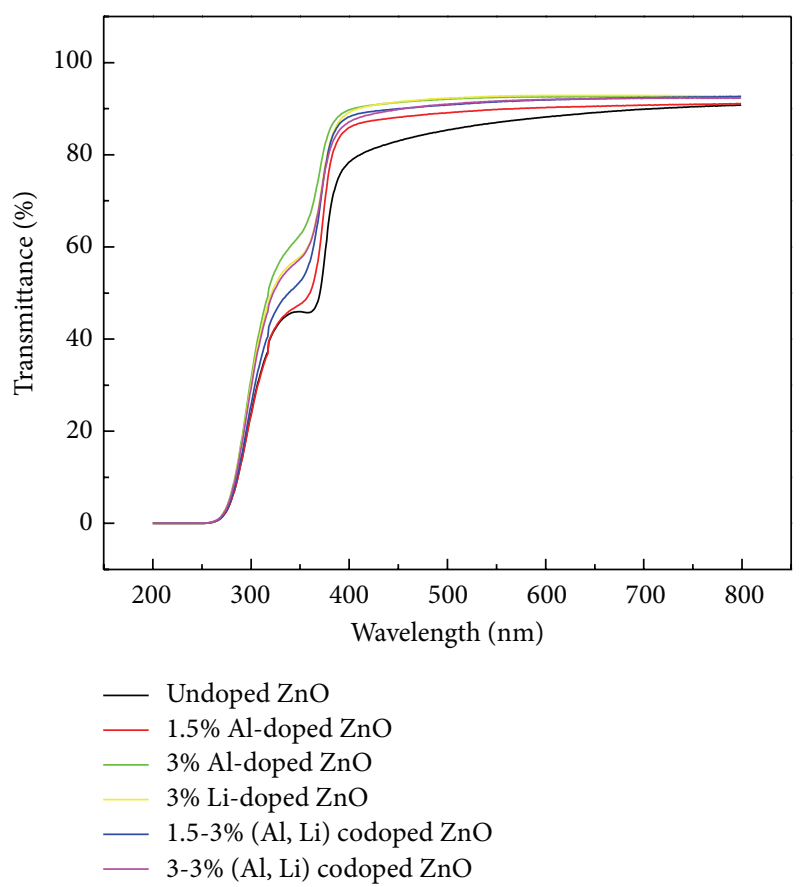

FIGURE 11: Transmittance spectra and the optical properties of $\mathrm{ZnO}$ films on glass substrates.

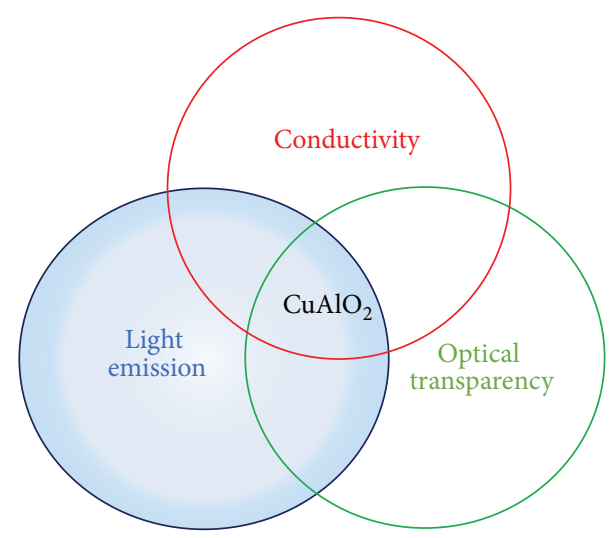

FIGURE 12: Proposed $\mathrm{CuAlO}_{2}$ nanostructured materials integrating three important functionalities.

with innovative morphologies and tailored properties. In the case of $\mathrm{CuAlO}_{2}$ study, which is basically inspired by urgent TCO development, we proposed a potential scheme of multifunctional nanobuilding blocks (Figure 12) which may pose future implications for emerging applications in the area of optoelectronics, thermoelectrics, catalyst, and nanophosphors.

Besides the investigation of near-band-edge emission, given the anisotropic electronic structure and higher conductivity along the basal plane, this delafossite material might be reviewed as a potential host material for luminescence applications. The large trivalent site in this structure is highly tunable and any modification on the trivalent site will unlikely degrade the overall p-type conductivity due to the strong confinement in this superlattice-resembled structure.

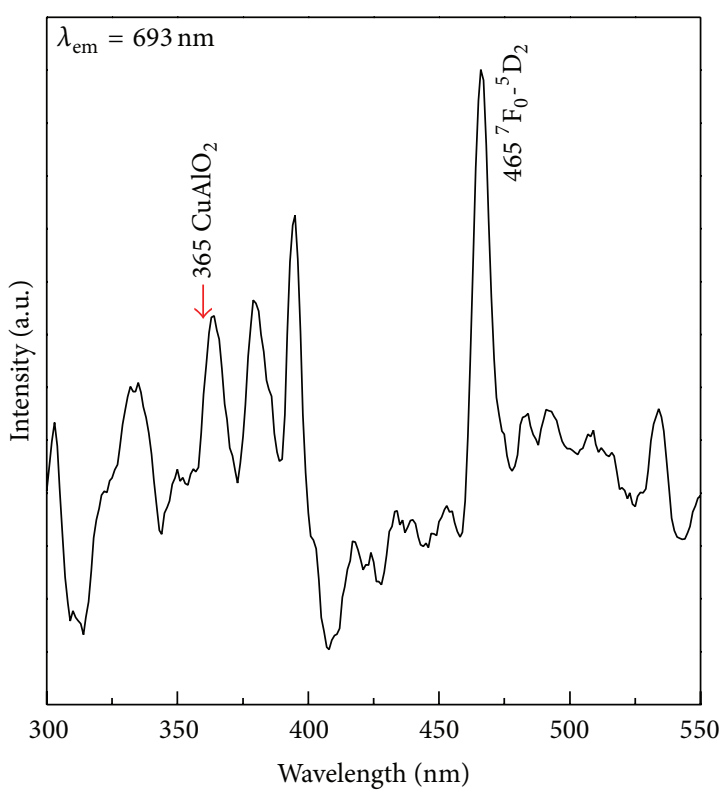

(a)

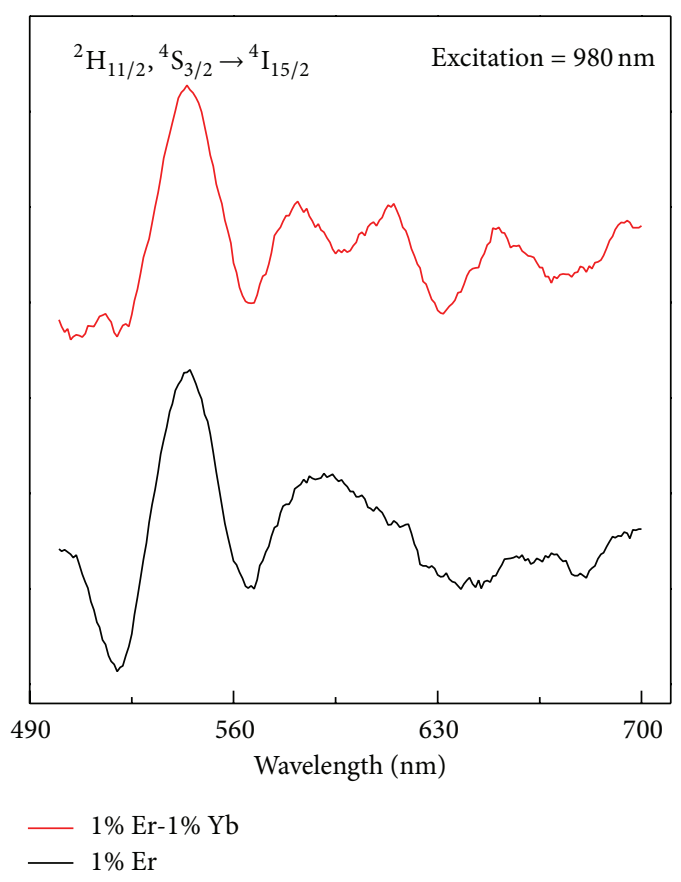

(b)

FIGURE 13: Photoluminescence spectra of $\mathrm{CuAlO}_{2}$ as host materials: (a) doped with $\mathrm{Eu}^{3+}$; (b) doped with $\mathrm{Er}^{3+}$ and $\mathrm{Yb}^{3+}$.

Figure 13 shows the characteristic photoluminescence from $\mathrm{Ln}^{3+}$ color centers. It could be seen that $\mathrm{CuAlO}_{2}$ indeed could act as an effective host material providing trivalent occupancy and it exhibited the capability of both downconversion and upconversion.

The intercalation of trivalent dopants was further examined by XPS as shown in Figure 14. The binding energies for $\mathrm{Cu} 2 \mathrm{p}_{3 / 2}$ are centered at $\sim 933.4 \mathrm{eV}$ with no shift observed with respect to Eu doping. It has been widely acknowledged that in the delafossite structure the strong two-dimensional 

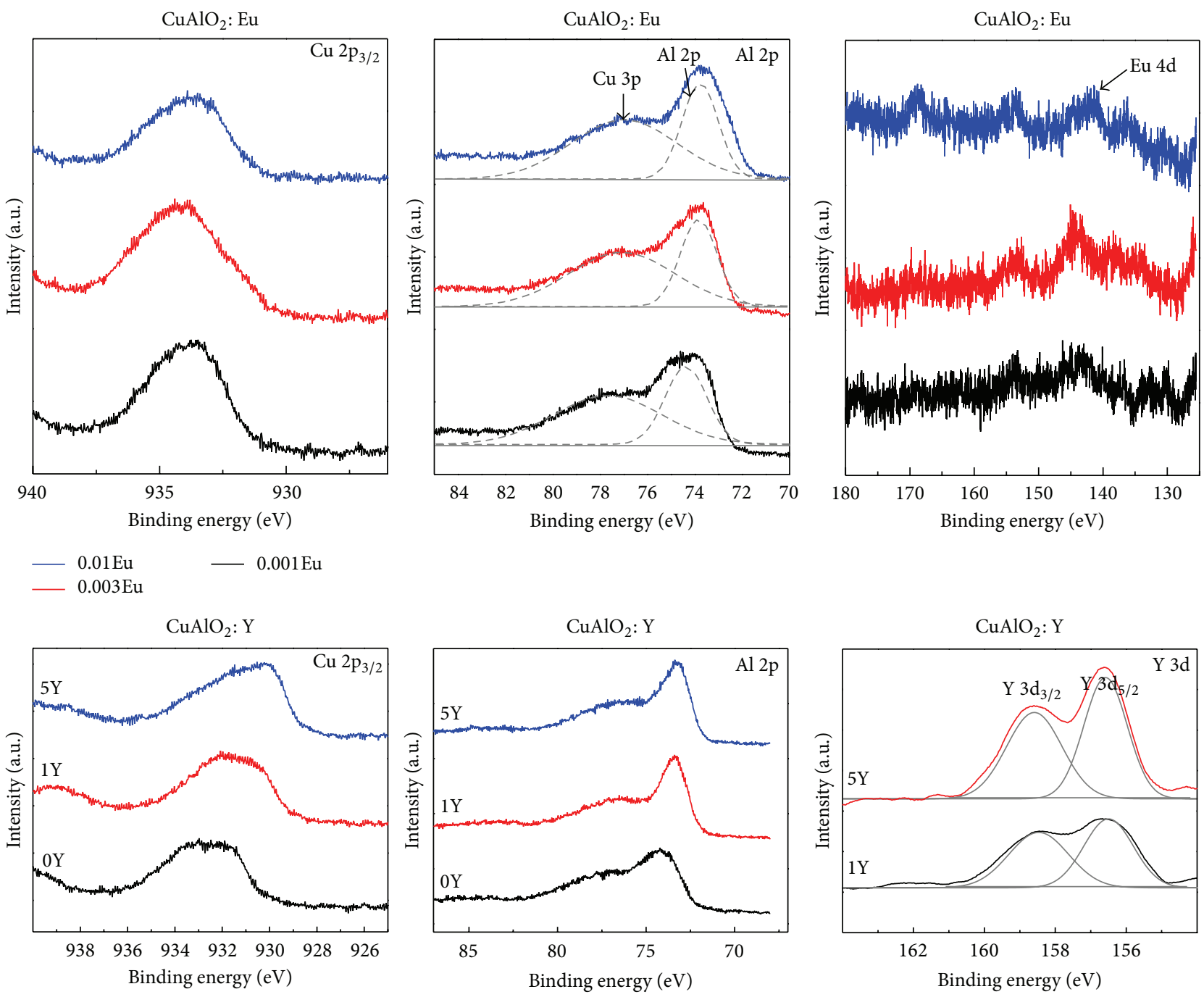

FIGURE 14: XPS core-level spectra of different sites in $\mathrm{CuAlO}_{2}$ hosts with different trivalent substitution.

confinement of $\mathrm{Cu}-\mathrm{O}$ bonds along $z$-axis restrains the electronic structure [53]. In contrast to $\mathrm{Cu} 2 \mathrm{p}_{3 / 2}$ peaks, $\mathrm{Al} 2 \mathrm{p}$ peaks shift to lower binding energies at higher dopant concentrations $(74.52 \mathrm{eV}$ for $x=0.001,74.09 \mathrm{eV}$ for $x=0.003$, and $73.54 \mathrm{eV}$ for $x=0.01$ ) due to the environment change around $\mathrm{MO}_{6}$ octahedra along the ab plane. The different $\mathrm{Cu}$ $2 \mathrm{p}_{3 / 2}$ and $\mathrm{Al} 2 \mathrm{p} \mathrm{BE}$ responses to trivalent ion substitution lead to the conjecture that the introduced rare earth within $\mathrm{MO}_{2}$ layer would insignificantly disturb the hole conduction path in $\mathrm{Cu}^{+}$layer. Therefore, the p-type conductivity might not be impaired. However, when examining the yttrium doping in the delafossite host, both $\mathrm{Cu}$ and $\mathrm{Al}$ peaks shifted to lower binding energies, indicating an overall weakening of binding environment after introducing yttrium ions. Our study [24] on the reduced mass of $\mathrm{Y}$ doped samples also confirms the observation from XPS.

Due to the strong $\mathrm{Cu}-\mathrm{O}$ dumbbell bond and the large $\mathrm{RE}$ ion radii, it is unlikely that the trivalent $\mathrm{RE}$ ions will occupy interstitial sites in the delafossite. On the other hand, a supplemental site occupancy of trivalent ions onto pristine $\mathrm{Al}$ site in $\mathrm{CuMO}_{2}$ delafossite could be revealed from the change of lattice parameters in terms of trivalent ionic radius [54]. The lattice constant increases pseudolinearly with the increase of $\mathrm{M}$ site ion radius, while the constant $c$ is independent of $\mathrm{M}$ site ion radius and should remain constant. Taking the case of Eu doping as an example, according to our host material, $\mathrm{CuAlO}_{2}$, the lattice constant could be estimated by $a=2.784 \times r_{R}+1.437$, in which the constant 2.784 was calculated from the $a$ value at zero doping level from the standard powder diffraction file (PDF\#35-1401). The trivalent ion radius $r_{R}$ follows a weighted sum of both $\mathrm{Al}^{3+}$ radius and $\mathrm{Eu}^{3+}$ radius $\left(r_{R}=(1-x) r_{\mathrm{Al}}+x r_{\mathrm{Eu}}\right)$ [55]. The calculated value is shown as a dashed line in Figure 15 and the experimental data is extracted from the Rietveld refinement of the delafossite phase $\mathrm{CuAl}_{1-x} \mathrm{Eu}_{x} \mathrm{O}_{2}$. The correlation between lattice constants and trivalent ionic radii generally follows the calculated rules, indicating the occupancy of extrinsic trivalent ions on the $\mathrm{Al}$ sites. 

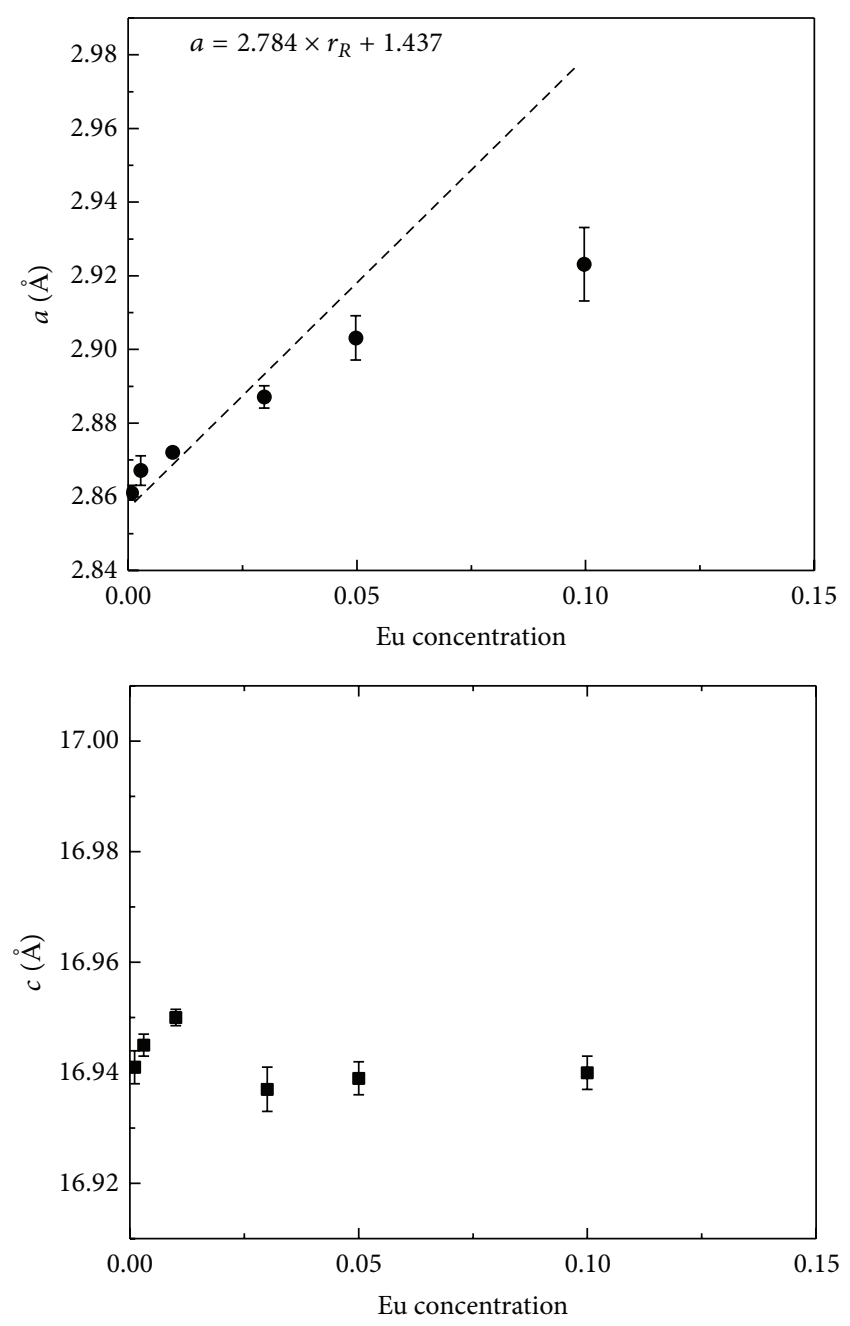

FIGURE 15: The lattice parameters of $a$ and $c$ of the 3R-polytype structure delafossite $\mathrm{CuAl}_{1-x} \mathrm{Eu}_{x} \mathrm{O}_{2}$ as a function of Eu concentration. The dash line shows the respective calculated $a$ values.

\section{Conclusion}

We have shown two case studies on p-type $\mathrm{CuAlO}_{2}$ and $\mathrm{ZnO}$, respectively, due to the high demand for developing p-type oxides with enhanced properties. Electrohydrodynamic processing is capable of fabricating both oxides with fine microstructures and comparable properties. The major advantages of employing electrospray and electrospinning are the low cost and versatility in materials selection and microstructure control. For the case of $\mathrm{CuAlO}_{2}$, electrospray through polyacrylamide route is feasible in obtaining highly crystallized TCO thin films at a lower temperature, while $\mathrm{CuAlO}_{2}$ electrospun fibers with improved visible transmittance could be fabricated in a similar way, yet in completely different morphologies. For $\mathrm{ZnO}$, even though there have been some reports on electrohydrodynamic processing, we testified the feasibility of codoping and observed a simultaneous improvement in surface smoothness and conductivity. The compensated Li exhibited the efficacy to mitigate the deficiencies introduced by degenerate doping. We believe that the electrohydrodynamic processing would be applied on a broader basis and would be beneficial to next-generation multifunctional materials.

\section{Conflict of Interests}

The authors declare that there is no conflict of interests regarding the publication of this paper.

\section{References}

[1] H. Fong, I. Chun, and D. H. Reneker, "Beaded nanofibers formed during electrospinning," Polymer, vol. 40, no. 16, pp. 4585-4592, 1999.

[2] A. L. Yarin, S. Koombhongse, and D. H. Reneker, "Taylor cone and jetting from liquid droplets in electrospinning of nanofibers," Journal of Applied Physics, vol. 90, no. 9, pp. 48364846, 2001.

[3] D. Li and Y. Xia, "Electrospinning of nanofibers: reinventing the wheel?" Advanced Materials, vol. 16, no. 14, pp. 1151-1170, 2004.

[4] W. Sigmund, J. Yuh, H. Park et al., "Processing and structure relationships in electrospinning of ceramic fiber systems," Journal of the American Ceramic Society, vol. 89, no. 2, pp. 395407, 2006.

[5] Y. Wu and R. L. Clark, "Electrohydrodynamic atomization: a versatile process for preparing materials for biomedical applications," Journal of Biomaterials Science, Polymer Edition, vol. 19, no. 5, pp. 573-601, 2008.

[6] Y. Liu, T. L. Olson, and Y. Wu, "Luminescence and microstructure of $\mathrm{Nd}$ doped $\mathrm{Y}_{2} \mathrm{Si}_{2} \mathrm{O}_{7}$ electrospun fibers," Journal of the American Ceramic Society, vol. 97, no. 8, pp. 2390-2393, 2014.

[7] H. Wu, L. Hu, M. W. Rowell et al., "Electrospun metal nanofiber webs as high-performance transparent electrode," Nano Letters, vol. 10, no. 10, pp. 4242-4248, 2010.

[8] D. Li and Y. Xia, "Direct fabrication of composite and ceramic hollow nanofibers by electrospinning," Nano Letters, vol. 4, no. 5, pp. 933-938, 2004.

[9] D. S. Ginley and C. Bright, "Transparent conducting oxides," MRS Bulletin, vol. 25, no. 8, pp. 15-18, 2000.

[10] H. Kim, J. S. Horwitz, W. H. Kim, A. J. Mäkinen, Z. H. Kafafi, and D. B. Chrisey, "Doped $\mathrm{ZnO}$ thin films as anode materials for organic light-emitting diodes," Thin Solid Films, vol. 420-421, pp. 539-543, 2002.

[11] Z. Q. Yao, B. He, L. Zhang et al., "Energy band engineering and controlled p-type conductivity of $\mathrm{CuAlO}_{2}$ thin films by nonisovalent Cu-O alloying," Applied Physics Letters, vol. 100, no. 6, Article ID 062102, 2012.

[12] T. Konry and R. S. Marks, "Physico-chemical studies of indium tin oxide-coated fiber optic biosensors," Thin Solid Films, vol. 492, no. 1-2, pp. 313-321, 2005.

[13] A. N. Banerjee and K. K. Chattopadhyay, "Recent developments in the emerging field of crystalline p-type transparent conducting oxide thin films," Progress in Crystal Growth and Characterization of Materials, vol. 50, no. 1-3, pp. 52-105, 2005.

[14] I. Hamada and H. Katayama-Yoshida, "Energetics of native defects in $\mathrm{CuAlO}_{2}$," Physica B: Condensed Matter, vol. 376-377, pp. 808-811, 2006.

[15] G. Thomas, "Materials science: invisible circuits," Nature, vol. 389, no. 6654, pp. 907-908, 1997. 
[16] F. N. Ishikawa, H.-K. Chang, K. Ryu et al., "Transparent electronics based on transfer printed aligned carbon nanotubes on rigid and flexible substrates," ACS Nano, vol. 3, no. 1, pp. 7379, 2009.

[17] H. Kawazoe, M. Yasukawa, H. Hyodo, M. Kurita, H. Yanagi, and H. Hosono, "P-type electrical conduction in transparent thin films of $\mathrm{CuAlO}_{2}$," Nature, vol. 389, no. 6654, pp. 939-942, 1997.

[18] M. S. Lee, T. Y. Kim, and D. Kim, "Anisotropic electrical conductivity of delafossite-type $\mathrm{CuAlO}_{2}$ laminar crystal," Applied Physics Letters, vol. 79, no. 13, pp. 2028-2030, 2001.

[19] G. Dong, M. Zhang, W. Lan, P. Dong, and H. Yan, "Structural and physical properties of $\mathrm{Mg}$-doped $\mathrm{CuAlO}_{2}$ thin films," Vacuum, vol. 82, no. 11, pp. 1321-1324, 2008.

[20] H. Jiang, X. Wang, X. Zang et al., "Electronic properties of bivalent cations ( $\mathrm{Be}, \mathrm{Mg}$ and $\mathrm{Ca}$ ) substitution for $\mathrm{Al}$ in delafossite $\mathrm{CuAlO}_{2}$ semiconductor by first-principles calculations," Journal of Alloys and Compounds, vol. 553, pp. 245-252, 2013.

[21] B.-W. Huang, C.-Y. Wen, G.-W. Lin et al., "Influence of $\mathrm{Ca} / \mathrm{Al}$ ratio on properties of amorphous/nanocrystalline $\mathrm{Cu}-\mathrm{Al}-\mathrm{Ca}-\mathrm{O}$ thin films," Journal of the American Ceramic Society, vol. 98, no. 1, pp. 125-129, 2015.

[22] D. O. Scanlon, A. Walsh, B. J. Morgan, G. W. Watson, D. J. Payne, and R. G. Egdell, "Effect of $\mathrm{Cr}$ substitution on the electronic structure of $\mathrm{CuAl}_{1-x} \mathrm{Cr}_{x} \mathrm{O}_{2}$," Physical Review B, vol. 79, no. 3, Article ID 035101, 2009.

[23] S. Zhao, M. Li, X. Liu, and G. Han, "Synthesis of $\mathrm{CuAlO}_{2}$ nanofibrous mats by electrospinning," Materials Chemistry and Physics, vol. 116, no. 2-3, pp. 615-618, 2009.

[24] Y. Liu, Y. Huang, H. J. Seo, and Y. Wu, "Blueshift in nearband-edge emission in $\mathrm{Y}^{3+}$-doped $\mathrm{CuAlO}_{2}$ nanofibers," Optical Materials Express, vol. 4, no. 12, pp. 2602-2607, 2014.

[25] G. Wang, S. Chu, N. Zhan, Y. Lin, L. Chernyak, and J. Liu, "ZnO homojunction photodiodes based on Sb-doped p-type nanowire array and n-type film for ultraviolet detection," Applied Physics Letters, vol. 98, no. 4, Article ID 041107, 2011.

[26] K. Mahmood, R. Munir, H. W. Kang, and H. J. Sung, "An atmospheric pressure-based electrospraying route to fabricate the multi-applications bilayer (AZO/ITO) TCO films," RSC Advances, vol. 3, no. 48, pp. 25741-25751, 2013.

[27] B. Liu, K. Nakata, M. Sakai et al., "Mesoporous $\mathrm{TiO}_{2}$ core-shell spheres composed of nanocrystals with exposed high-energy facets: facile synthesis and formation mechanism," Langmuir, vol. 27, no. 13, pp. 8500-8508, 2011.

[28] D. Li and Y. Xia, "Fabrication of titania nanofibers by electrospinning," Nano Letters, vol. 3, no. 4, pp. 555-560, 2003.

[29] Z. Liu, D. D. Sun, P. Guo, and J. O. Leckie, "An efficient bicomponent $\mathrm{TiO}_{2} / \mathrm{SnO}_{2}$ nanofiber photocatalyst fabricated by electrospinning with a side-by-side dual spinneret method," Nano Letters, vol. 7, no. 4, pp. 1081-1085, 2007.

[30] Z. Zhang, C. Shao, X. Li et al., "Electrospun nanofibers of $\mathrm{ZnO}-\mathrm{SnO}_{2}$ heterojunction with high photocatalytic activity," The Journal of Physical Chemistry C, vol. 114, no. 17, pp. 79207925, 2010.

[31] Y. Ding, Y. Wang, L. Zhang, H. Zhang, and Y. Lei, "Preparation, characterization and application of novel conductive $\mathrm{NiO}$ CdO nanofibers with dislocation feature," Journal of Materials Chemistry, vol. 22, no. 3, pp. 980-986, 2012.

[32] O. Wilhelm, S. E. Pratsinis, D. Perednis, and L. J. Gauckler, "Electrospray and pressurized spray deposition of yttriastabilized zirconia films," Thin Solid Films, vol. 479, no. 1-2, pp. 121-129, 2005.
[33] A.-M. Azad, "Fabrication of yttria-stabilized zirconia nanofibers by electrospinning," Materials Letters, vol. 60, no. 1, pp. 6772, 2006.

[34] Y. Matsushima, T. Yamazaki, K. Maeda, and T. Suzuki, "Fabrication of $\mathrm{SnO}_{2}$ particle-layers using the electrospray method and gas sensing properties for $\mathrm{H}_{2}$," Journal of Electroceramics, vol. 13 , no. 1-3, pp. 765-770, 2004.

[35] A. Hosseinmardi, N. Shojaee, M. Keyanpour-Rad, and T. Ebadzadeh, "A study on the photoluminescence properties of electrospray deposited amorphous and crystalline nanostructured $\mathrm{ZnO}$ thin films," Ceramics International, vol. 38, no. 3, pp. 1975-1980, 2012.

[36] A. M. Bazargan, S. M. A. Fateminia, M. E. Ganji, and M. A. Bahrevar, "Electrospinning preparation and characterization of cadmium oxide nanofibers," Chemical Engineering Journal, vol. 155, no. 1-2, pp. 523-527, 2009.

[37] X. Yang, C. Shao, Y. Liu, R. Mu, and H. Guan, "Nanofibers of $\mathrm{CeO}_{2}$ via an electrospinning technique," Thin Solid Films, vol. 478, no. 1-2, pp. 228-231, 2005.

[38] G. Larsen, R. Velarde-Ortiz, K. Minchow, A. Barrero, and I. G. Loscertales, "A method for making inorganic and hybrid (organic/inorganic) fibers and vesicles with diameters in the submicrometer and micrometer range via sol-gel chemistry and electrically forced liquid jets," Journal of the American Chemical Society, vol. 125, no. 5, pp. 1154-1155, 2003.

[39] J. Zhao, W. Zhang, E. Xie, Z. Ma, A. Zhao, and Z. Liu, "Structure and photoluminescence of $\beta-\mathrm{Ga}_{2} \mathrm{O}_{3}: \mathrm{Eu}^{3+}$ nanofibers prepared by electrospinning," Applied Surface Science, vol. 257, no. 11, pp. 4968-4972, 2011.

[40] Y. Mizuno, E. Hosono, T. Saito et al., "Electrospinning synthesis of wire-structured $\mathrm{LiCoO}_{2}$ for electrode materials of highpower Li-ion batteries," The Journal of Physical Chemistry C, vol. 116, no. 19, pp. 10774-10780, 2012.

[41] C. Shao, H. Guan, Y. Liu, and R. Mu, "MgO nanofibres via an electrospinning technique," Journal of Materials Science, vol. 41, no. 12, pp. 3821-3824, 2006.

[42] K. R. Murali and M. Balasubramanian, "Properties of $\mathrm{CuAlO}_{2}$ thin films deposited by polyacrylamide gel route," Materials Science in Semiconductor Processing, vol. 16, no. 1, pp. 38-42, 2013.

[43] K. T. Jacob and C. B. Alcock, "Thermodynamics of $\mathrm{CuAlO}_{2}$ and $\mathrm{CuAl}_{2} \mathrm{O}_{4}$ and phase equilibria in the system $\mathrm{Cu}_{2} \mathrm{O}-\mathrm{CuO}-\mathrm{Al}_{2} \mathrm{O}_{3}$," Journal of the American Ceramic Society, vol. 58, no. 5-6, pp. 192-195, 1975.

[44] R.-S. Yu, S.-C. Liang, C.-J. Lu, D.-C. Tasi, and F.-S. Shieu, "Characterization and optoelectronic properties of p-type Ndoped $\mathrm{CuAlO}_{2}$ films," Applied Physics Letters, vol. 90, no. 19, Article ID 191117, 2007.

[45] D. O. Scanlon and G. W. Watson, "Conductivity limits in $\mathrm{CuAlO}_{2}$ from screened-hybrid density functional theory," The Journal of Physical Chemistry Letters, vol. 1, no. 21, pp. 3195-3199, 2010.

[46] N. Tsuboi, T. Hoshino, H. Ohara et al., "Control of luminescence and conductivity of delafossite-type $\mathrm{CuYO}_{2}$ by substitution of rare earth cation $(\mathrm{Eu}, \mathrm{Tb})$ and/or Ca cation for Y cation," Journal of Physics and Chemistry of Solids, vol. 66, no. 11, pp. 2134-2138, 2005.

[47] W. Bu, Z. Hua, H. Chen, and J. Shi, "Epitaxial synthesis of uniform cerium phosphate one-dimensional nanocable heterostructures with improved luminescence," The Journal of Physical Chemistry B, vol. 109, no. 30, pp. 14461-14464, 2005. 
[48] G. Jia, Y. Zheng, K. Liu, Y. Song, H. You, and H. Zhang, "Facile surfactant- and template-free synthesis and luminescent properties of one-dimensional $\mathrm{Lu}_{2} \mathrm{O}_{3}: \mathrm{Eu}^{3+}$ phosphors," The Journal of Physical Chemistry C, vol. 113, no. 1, pp. 153-158, 2009.

[49] J. Yang, C. Li, Z. Cheng et al., "Size-tailored synthesis and luminescent properties of one-dimensional $\mathrm{Gd}_{2} \mathrm{O}_{3}: \mathrm{Eu}^{3+}$ nanorods and microrods," Journal of Physical Chemistry C, vol. 111, no. 49, pp. 18148-18154, 2007.

[50] S.-Y. Kuo, W.-C. Chen, F.-I. Lai et al., "Effects of doping concentration and annealing temperature on properties of highlyoriented Al-doped ZnO films," Journal of Crystal Growth, vol. 287, no. 1, pp. 78-84, 2006.

[51] T. Yamamoto, "Codoping method for solutions of doping problems in wide-band-gap semiconductors," Physica Status Solidi (A), vol. 193, no. 3, pp. 423-433, 2002.

[52] T. Yamamoto and H. Katayama-Yoshida, "Physics and control of valence states in $\mathrm{ZnO}$ by codoping method," Physica B: Condensed Matter, vol. 302-303, pp. 155-162, 2001.

[53] A. Narayan Banerjee, S. W. Joo, and B.-K. Min, "Quantum size effect in the photoluminescence properties of p-type semiconducting transparent $\mathrm{CuAlO}_{2}$ nanoparticles," Journal of Applied Physics, vol. 112, no. 11, Article ID 114329, 2012.

[54] K. Isawa, Y. Yaegashi, M. Komatsu et al., "Synthesis of delafossite-derived phases, $R \mathrm{CuO}_{2+\delta}$ with $R=Y$, La, Pr, Nd, $\mathrm{Sm}$, and Eu, and observation of spin-gap-like behavior," Physical Review B, vol. 56, no. 6, pp. 3457-3466, 1997.

[55] M. K. Chong, K. Pita, and C. H. Kam, "Photoluminescence of sol-gel-derived $\mathrm{Y}_{2} \mathrm{O}_{3}: \mathrm{Eu}^{3+}$ thin-film phosphors with $\mathrm{Mg}^{2+}$ and $\mathrm{Al}^{3+}$ co-doping," Applied Physics A, vol. 79, no. 3, pp. 433-437, 2004. 

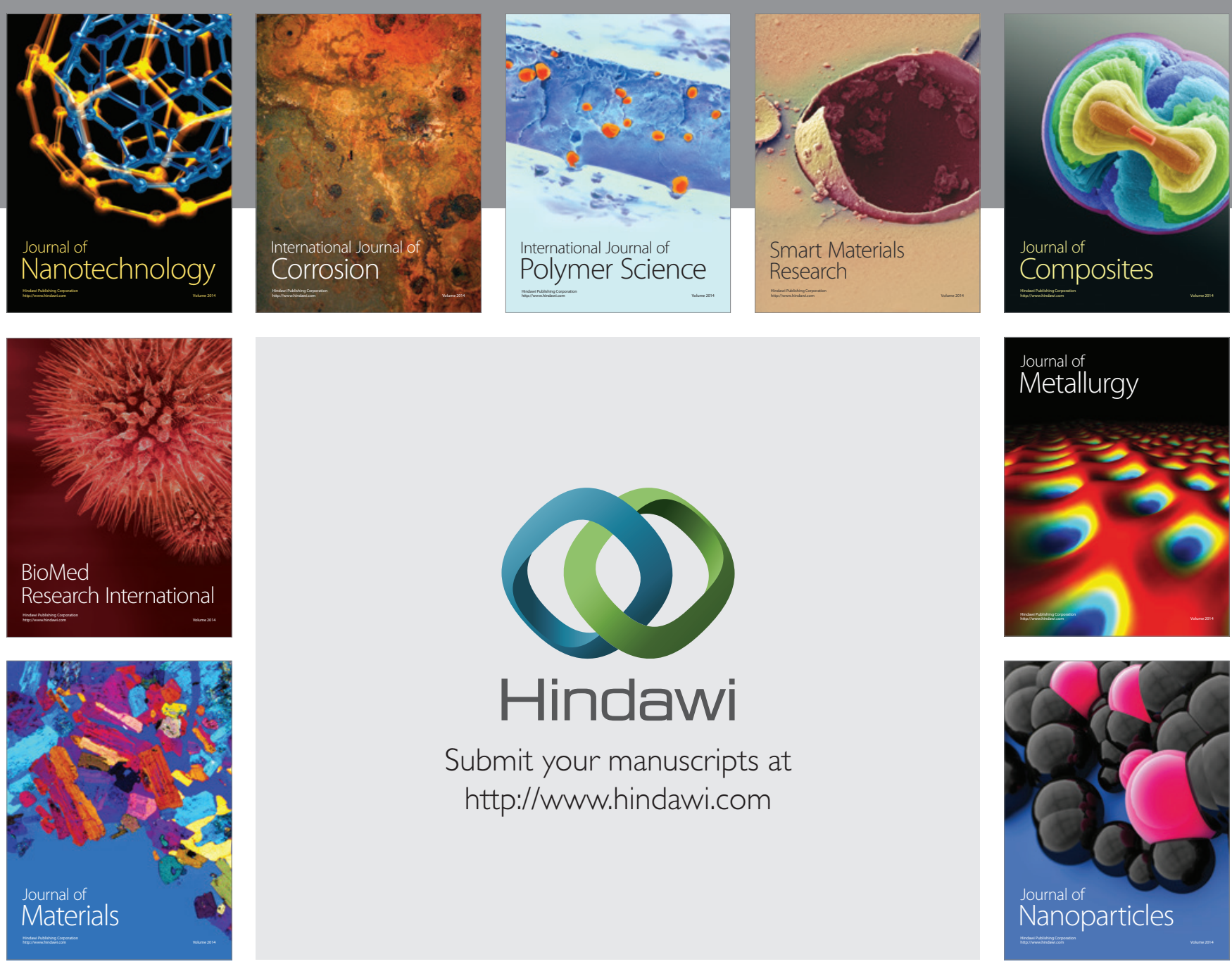

Submit your manuscripts at http://www.hindawi.com
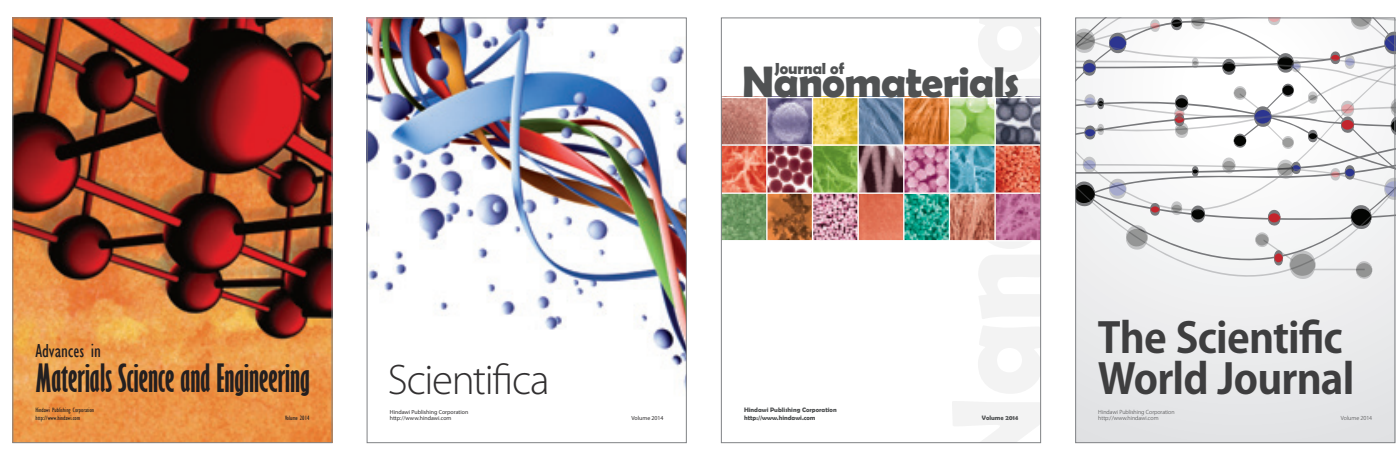

\section{The Scientific World Journal}
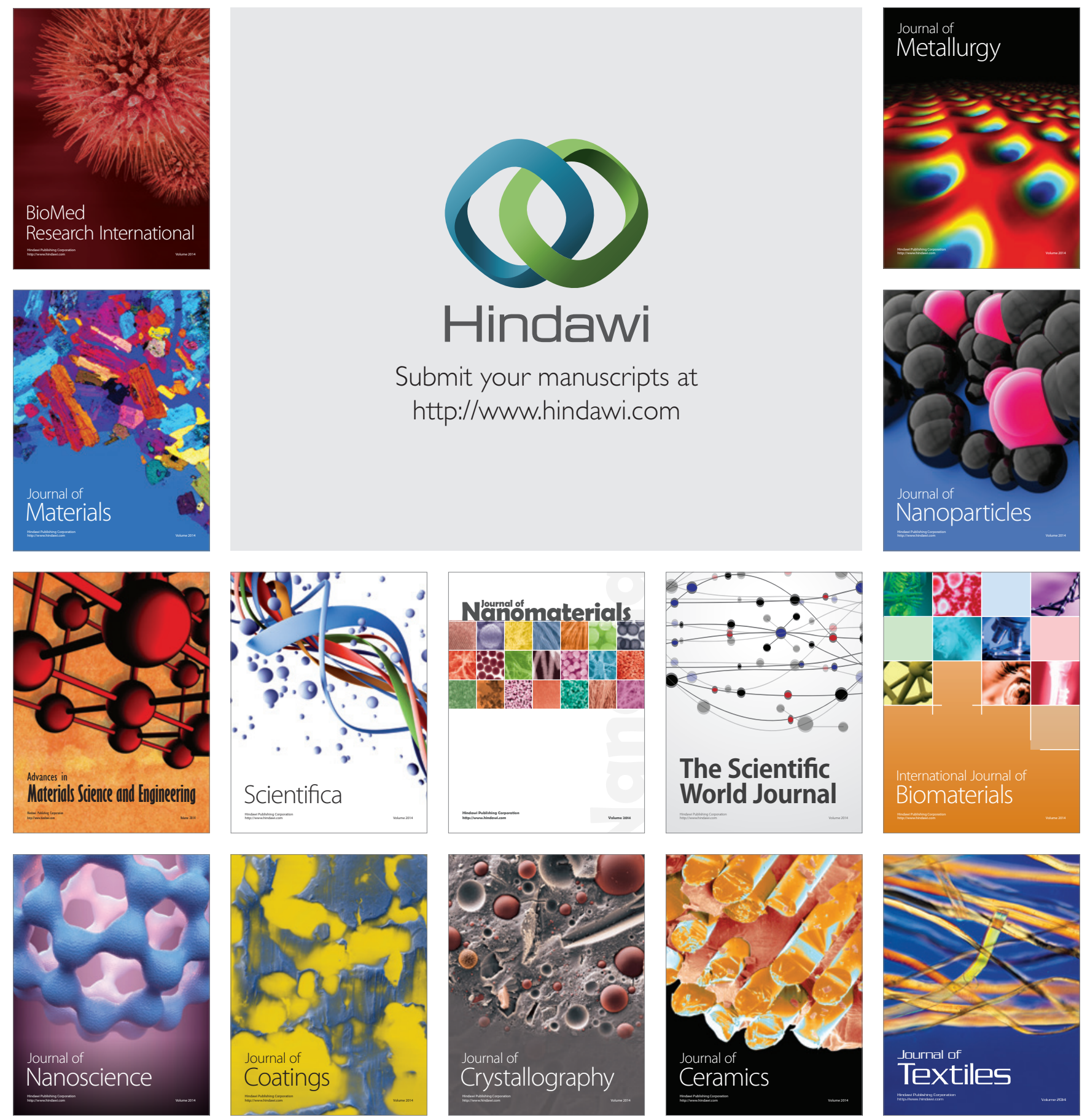